Esta revista forma parte del acervo de la Biblioteca Jurídica Virtual del Instituto de Investigaciones Jurídicas de la UNAM

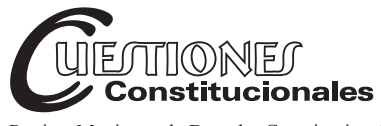

Revista Mexicana de Derecho Constitucional

Núm. 44, Enero-Junio 2021

ISSN (versión electrónica): 2448-4881

\title{
Modelos de legitimación procesal constitucional en las entidades federativas en México: Una mirada al federalismo procesal constitucional
}

\author{
Models of constitutional procedural legitimacy in the federal \\ entities in Mexico: A look at constitutional procedural federalism
}

Recepción: 11 de febrero de 2020

Aceptación: 31 de agosto de 2020

\section{Mauro Arturo RIVERA LEÓN*}

RESUMEN: El presente artículo analiza los modelos de legitimación en acciones de inconstitucionalidad y controversias constitucionales establecidos por las diversas Entidades Federativas en el caso mexicano. El estudio argumenta que, dado el federalismo mexicano, Alemania es un adecuado término de comparación por ser un Estado Federal con modelos operativos de justicia constitucional local concentrada en los Länder. Sin embargo, el modelo alemán parte de una articulación constitucional. A diferencia del modelo alemán, el caso mexicano, no ha permitido generar estancos competenciales separados y se ha caracterizado por una competencia basada en la primacía y no el deslinde. Se concluye que, a falta de un adecuado deslinde de competencias en un federalismo procesal constitucional, la única esperanza para la operatividad de los
ABSTRACT: This article analyzes the legal standing models in constitutional control mechanisms established by the states in the Mexican case. The author argues that given Mexican federalism, Germany stands as an adequate comparative point. That is, Germany is a Federal State that has established operative models of constitutional control in the Länder. However, the German model has a clear competence distribution between its federal and State constitutional jurisdiction. Unlike the German model, the Mexican model is characterized by the primacy of the Federal system and not the distribution of competences. The author concludes that in the absence of a clear distribution of competences, establishing new subjects with legal standing is the only hope towards the operation of local models.

* Profesor de Derecho en la Universidad Iberoamericana. México. Correo electrónico: arturo.riverale@gmail.com ORCID: 0000-0003-4964-7086

Cuestiones Constitucionales, Núm. 44, Enero-Junio 2021

ISSN: $2448-4881$ 
Esta revista forma parte del acervo de la Biblioteca Jurídica Virtual del Instituto de Investigaciones Jurídicas de la UNAM

modelos locales es generar incentivos para su empleo, como la legitimación de sujetos no contemplados en el esquema federal y no la simple duplicidad de legitimaciones.

Palabras clave: Procesal constitucional, federalismo y entidades federativas.
Keywords: Constitutional procedure, federalism, and federative entities.

SUMARIO: I. Breve introducción a la justicia constitucional local. II. El modelo alemán como término de comparación. III. La legitimación en las controversias constitucionales locales. IV. La legitimación en las acciones de inconstitucionalidad en las entidades federativas. V. Consideraciones finales. VI. Fuentes consultadas.

\section{BREVE INTRODUCCIÓN A LA JUSTICIA CONSTITUCIONAL LOCAL}

\section{El nacimiento de un control constitucional local}

Los modelos de control constitucional locales en México son novedosos. Es paradójico pensar que, pese a la ausencia de medios de control local, el juicio de amparo (medio de control constitucional mexicano por antonomasia) proviene de la Constitución yucateca de 1841, aunque nunca alcanzara operatividad local. Fuera del brillante antecedente de Crescencio Rejón, las constituciones locales carecieron de una garantía jurisdiccional autónoma. Fue el propio juicio de amparo federal, a través de vías indirectas, el encargado de dotarlas de cierta operatividad relativa.

El desinterés por la justicia constitucional local y en general por el constitucionalismo local en México es relativamente sencillo de explicar, en tanto las constituciones locales se imbricaron en la misma dinámica que la Constitución federal. La norma fundamental era concebida más como una directriz política o un programa de actuación legitimador del poder en turno, que como una norma jurídica cuyos preceptos fuesen de aplicación directa. La misma situación acontecía con las Constituciones de las Entidades Federativas. Bajo estas circunstancias, es comprensible que una garantía jurisdiccional local no se viese como una necesidad indispensable (Rivera, 2015: 17-44). 
Esta revista forma parte del acervo de la Biblioteca Jurídica Virtual del Instituto de Investigaciones Jurídicas de la UNAM

El control jurisdiccional local mexicano, así, es de un carácter reciente. A pesar de que algunas Entidades Federativas nominalmente consagraron la existencia de "controversias constitucionales" análogas al modelo federal, éstas nunca gozaron de operatividad o regulación y difícilmente podrían ser considerados modelos propios de control jurisdiccional.

No puede negarse que, como afirma Ríos (2001: 374), una de las razones principales para consagrar sistemas de justicia constitucional local es el pluralismo político. Previamente, el régimen de partido único solventaba las disputas políticas no mediante mecanismos jurídicos sino jerárquicamente con la cúpula partidista. Ante ello, el Poder Judicial (nombrado por el poder político en turno) se veía como un actor prescindible para la solución de conflictos. Sin embargo, el pluralismo ha vuelto de nueva cuenta los ojos a la judicatura en la búsqueda de un árbitro imparcial que solvente los conflictos políticos.

El desarrollo de la justicia constitucional local mexicana inicia con la reforma constitucional del Estado de Veracruz en el año 2000. La instauración de un modelo propio de jurisdicción constitucional en dicha entidad desató una ola de reformas en diversas Entidades Federativas cuya rápida y sucesiva expansión ha reavivado notablemente el debate sobre la garantía local de la Constitución, como señalaron Ferrer Mac-Gregor (2003: 229) y Arteaga (2002: 16).

A pesar de que las acciones de inconstitucionalidad y las controversias constitucionales son los instrumentos de control más frecuentes (Báez y Cienfuegos, 2001: 38), también se han previsto las omisiones legislativas (Chiapas, Veracruz, Tlaxcala y Quintana Roo), la cuestión de inconstitucionalidad (Veracruz y Coahuila) y el sumamente debatido amparo local (Veracruz y Tlaxcala). La gran mayoría de Estados prevé en la actualidad mecanismos de control siendo los últimos en su incorporación la Ciudad de México y Sonora. ${ }^{1}$

1 Sin duda, entre los Estados con mecanismos de control, Sonora es el Estado con mayores problemáticas de configuración. La redacción de la Constitución sonorense (artículo 166) evidencia fuertes problemas de entendimiento del modelo. Por ejemplo, las controversias constitucionales, pueden promoverse por el fiscal general en materia penal (sea o no relacionada al ámbito de sus funciones, lo que evidencia la falta de entendimiento conceptual de la controversia como proceso de conflicto y no de control abstracto). Aunado a ello, se establecieron legitimaciones altísimas para la presentación de la acción de inconstitucionalidad (35\% de los integrantes del Congreso o el mismo porcentaje del total de ayuntamientos), y se estableció la procedencia de la acción en contra de "puntos 
Esta revista forma parte del acervo de la Biblioteca Jurídica Virtual del Instituto de Investigaciones Jurídicas de la UNAM

El surgimiento de estos medios de control puede juzgarse positivo fundamentalmente por dos razones. 1) El control jurisdiccional de la constitucionalidad local implica, como corolario, la consideración del carácter de norma jurídica a la Constitución local como norma fundante de su propio ámbito. 2) En segundo lugar, la jurisdicción constitucional fortalece el federalismo dado que permite la tutela de las instituciones locales y fomenta la solución interna de disputas, minorando así la posición prototípica super partes de la jurisdicción constitucional federal en las entidades federativas.

Si se da un adecuado funcionamiento de los medios de control y los actores políticos son capaces de encontrar soluciones a los conflictos dentro de la justicia constitucional local, debemos percibir entonces un marcado indicio de un federalismo fortalecido; una reivindicación histórica del origen local de la paradigmática garantía jurisdiccional de la Constitución mexicana (Astudillo, 2006: p. 13).

\section{Articulaciones y duplicidades}

\section{A. La importancia de una correcta articulación entre la jurisdicción constitucional federal y local}

Lejos se encuentra este trabajo de pretender fijar una postura sobre el complejo encaje entre las distintas jurisdicciones de control constitucional o "federalismo judicial constitucional" en el entendimiento de Bustillos (2013: p. 106). Otros trabajos, como el de Coello (2008: p. 783 y ss.) se han ocupado de forma mucho más exhaustiva sobre este difícil tema, al menos acotados al caso mexicano. Sin embargo, sí pretendemos recalcar que la legitimación procesal constitucional local depende para su funcionamiento de un urgente marco que permita congeniar los distintos ámbitos de control en beneficio de la garantía jurisdiccional de la Constitución (Uribe y Montes, 2011: 278).

Si la jurisdicción constitucional federal puede erigirse en revisor absoluto de las resoluciones de la justicia constitucional local ${ }^{2}$, entonces la

de acuerdo" (lo que es controversial tomando en cuenta su ausencia de carácter normativo o de vinculación por ser meros instrumentos políticos). Si a las dificultades del control constitucional local se suman las inadecuadas configuraciones, parece seguro que el sistema sonorense no tendrá operatividad.

2 Por ejemplo, la controversia constitucional se considera procedente para combatir

Cuestiones Constitucionales, Núm. 44, Enero-Junio 2021

ISSN: $2448-4881$ 
Esta revista forma parte del acervo de la Biblioteca Jurídica Virtual del Instituto de Investigaciones Jurídicas de la UNAM

provisionalidad de aquélla desincentivará el uso de sus mecanismos de control, pues los actores políticos preferirán recurrir a un árbitro con capacidad definitiva para solucionar el conflicto (máxime cuando la resolución de estos conflictos es usualmente larga).

Dado que la legitimación en controversias constitucionales y acciones de inconstitucionalidad local se moldeará, en buena medida, bajo el parámetro de la Constitución federal, vale la pena recordar las características de tal legitimación y los sujetos legitimados.

La legitimación en controversias constitucionales a nivel federal tiene por características la naturaleza constitucional, textura cerrada y previsión de las relaciones intersubjetivas (Rivera, 2016: 31 y ss.). Por naturaleza constitucional, debe entenderse que la legitimación dimana del propio texto constitucional y, por tanto, no puede ser restringida o ampliada en la legislación secundaria. La textura cerrada implica que se ha previsto un elenco de sujetos definidos de forma expresa, sin aludir a una categoría genérica de sujetos cuya interpretación puntual pueda incorporar nuevos sujetos legitimados. Finalmente, por previsión de las relaciones intersubjetivas debe entenderse que la propia Constitución define la forma en que puede entablarse la litis (cuál sujeto puede demandar a cuál sujeto). Sustantivamente, se contempla la posibilidad de plantear conflictos entre órdenes de gobierno (Federación, entidades federativas y municipios); conflictos entre los poderes de una misma entidad federativa, municipios o demarcaciones de la Ciudad de México.

Finalmente, a nivel de órganos vértices federales, tienen legitimación los órganos constitucionales autónomos, el Poder Ejecutivo y el Congreso de la Unión (entendiéndose la posibilidad de que cada cámara plantee la controversia constitucional autónomamente). La diversa legitimación en controversias constitucionales denota las tres funciones que ésta realiza, a saber, conflictos orgánicos verticales, conflictos orgánicos horizontales y conflictos limítrofes predicables mayormente del ámbito municipal (Rivera, 2017: 1666).

algunas resoluciones de la jurisdicción constitucional local. Existe una tesis que sostiene: "Controversias constitucionales. No son la vía idónea para combatir resoluciones jurisdiccionales" (Novena Época, Segunda Sala, Semanario Judicial de la Federación y su Gaceta, T. VII, junio de 1998, tesis 2a LXXXVII/98, p. 421). De cualquier forma, el nuevo proceso sería procedente si las partes de la nueva controversia constitucional federal fueron, a su vez, partes en la antigua controversia, o son sujetos enumerados en el artículo 105.I, como afirma Coello (2006: 335). 
Esta revista forma parte del acervo de la Biblioteca Jurídica Virtual del Instituto de Investigaciones Jurídicas de la UNAM

Por su parte, la legitimación establecida en la acción de inconstitucionalidad a nivel federal tiene por características la naturaleza constitucional, textura cerrada o numerus clausus y carácter mayoritariamente institucional de los sujetos legitimados. Las primeras dos características se han explicado al hilo de la controversia constitucional. La última de ellas, implica que los sujetos legitimados pertenecen en su mayoría al Estado-aparato (salvo excepción de los partidos políticos). En el caso de la acción de inconstitucionalidad, la legitimación se reserva al elevado porcentaje 33\% del cuerpo parlamentario que emitió la norma (Rivera, 2017: 225), el Poder Ejecutivo federal, los partidos políticos locales o nacionales contra normas expedidas en su ámbito de validez, la Comisión Nacional de los Derechos Humanos y sus homólogos en las entidades federativas (éstos últimos sólo respecto de normas locales), los órganos de acceso a la información federales y locales (sólo respecto de normas locales) y, por último, el fiscal general de la República ${ }^{3}$ respecto de normas penales, procesales penales y aquéllas relacionadas con el ámbito de sus funciones.

\section{B. Duplicidad de legitimaciones}

Teniendo lo anterior presente, es sencillo constatar que la actual configuración de legitimaciones procesales en las distintas entidades federativas ofrece múltiples ocasiones para la duplicidad. En varios casos, el mismo actor se encuentra legitimado para acudir tanto a la jurisdicción federal como a la jurisdicción local. El escaso número asuntos que hasta la fecha se han resuelto definitivamente por la jurisdicción constitucional local, como en su momento demostró Bustillos (2009: 29-71) debe ser prueba no sólo de la necesidad de una mejora en la configuración normativa de dichos mecanismos, sino en la urgencia de una revalorización de dichos mecanismos por parte de los propios sujetos legitimados.

En el caso de la duplicidad de legitimaciones, naturalmente, la divergencia juega un peso fuerte. Un actor que a nivel federal no tiene legitimación para impugnar una norma o un acto, pero sí la goza a nivel local, evidentemente tendrá un fuerte incentivo para utilizar el mecanismo, sim-

3 Debe recordarse que el 20 de diciembre de 2018 entró en vigor la reforma constitucional concerniente a la Fiscalía General de la República y, por tanto, se modificó el vigor del propio artículo 105 constitucional. Anteriormente, se consagraba legitimación universal en favor del procurador general de la República y el Ejecutivo federal carecía de ella. 
Esta revista forma parte del acervo de la Biblioteca Jurídica Virtual del Instituto de Investigaciones Jurídicas de la UNAM

plemente porque es el único que puede utilizar. En cambio, cuando el actor se encuentra ante una elección optativa ¿existe realmente algún incentivo para que acuda ante una sala constitucional, Pleno o Tribunal Constitucional local cuya creación es reciente y sin la seguridad de una solución definitiva del asunto?

El peso de la optatividad se deja sentir con mayor fuerza en los conflictos de atribuciones. El municipio ha sido el gran promotor de controversias constitucionales teniendo a la Suprema Corte como árbitro predilecto. Quizá aún la joven jurisdicción constitucional local no se ha consolidado al grado de poder considerarla como principal titular de la facultad de conflictos internos, pero los notables esfuerzos emprendidos por diversas entidades federativas deberían abrir el debate nacional para articular desde el propio texto constitucional un modelo de jurisdicción constitucional comprehensivo del ámbito localista.

Han sido los esfuerzos "aislados" de entidades federativas como Veracruz los que han contribuido en gran medida a revitalizar el debate del constitucionalismo local, pero sólo un esfuerzo integral puede producir resultados tangibles. No parece descabellado pensar que la jurisdicción constitucional federal pudiera desprenderse de competencias a favor de jurisdicciones constitucionales locales consolidadas, sobre todo en ámbitos propios y específicos de éstas. Si estableciésemos un principio de subsidiariedad federal, podríamos a través de la cooperación y la división de trabajo, descargar asuntos a la jurisdicción federal y homogeneizar criterios mediante un diálogo entre los diferentes tribunales.

La legitimación de comisiones estatales de derechos humanos para impugnar leyes de su respectiva entidad, es un buen ejemplo de una competencia que potencialmente podría cederse a la justicia constitucional local. Inclusive, podría abrirse un nuevo ámbito de legitimaciones cuyo encaje actual en el modelo federal es dudoso.

Teniendo como ejes básicos de análisis la articulación de jurisdicciones y la legitimación, resulta notable que la primera decisión en un proceso de control constitucional local puro (acción de inconstitucionalidad 1/2001, Veracruz) haya sido una inadmisión de la demanda por falta de legitimación activa del promovente. En efecto, dado que la presentación de la acción de inconstitucionalidad se dio por parte de una persona física y no un sujeto legitimado, el Pleno del Tribunal omitió correctamente entrar al fondo del asunto. Dicha resolución fue confirmada con posterioridad en amparo 
Esta revista forma parte del acervo de la Biblioteca Jurídica Virtual del Instituto de Investigaciones Jurídicas de la UNAM

directo por el Segundo Tribunal Colegiado en Materia Civil del Séptimo Circuito (Amparo directo 666/2001). La decisión no puede hablarnos de una incorrecta configuración del modelo veracruzano, pues salvaguarda una opción legítima de restringir los medios de control constitucional abstractos a entidades públicas. Sí debe, en cambio, vaticinar que la legitimación será uno de los grandes debates en la justicia constitucional local.

Empleando las características que previamente hemos referido respecto del modelo federal de jurisdicción constitucional, emprenderemos el estudio de la legitimación en la acción de inconstitucionalidad y controversias constitucionales locales.

Realizaremos el estudio de las legitimaciones locales privilegiando como criterio de estudio el sujeto legitimado y no la enumeración de sujetos legitimados por Entidad Federativa buscando los puntos globales de simetría y diferencia. Antes, empero, haremos una breve incursión al modelo alemán que ha desarrollado un sistema de justicia constitucional local funcional.

\section{EL MODELO ALEMÁN COMO TÉRMINO DE COMPARACIÓN}

En el marco de modelos comparados, Alemania se presenta como un posible contraste potencial en justicia constitucional local. Una primera razón para abordar la comparación es que Alemania es un Estado federal, al igual que México. Dentro de su federalismo, ha desarrollado un exitoso modelo de justicia constitucional local funcional. En la comparación, se tomarán en cuenta los formantes del ordenamiento, a saber, la normativa (constitucional o secundaria), la doctrina y la jurisprudencia (Sacco, 1992: 343 y ss.). Aunado a ello, debe tomarse en cuenta la existencia de criptotipos; reglas no escritas que condicionan la actitud de los operadores frente al poder normativo (Pegoraro, 2017: 66 y Somma, 2015: 160).

En el caso alemán, existen criptotipos derivados del origen histórico de un modelo de conflictos competenciales consagrado previo a Weimar, lo que precondiciona la adopción de soluciones que permitan la defensa competencial. De igual forma, históricamente los Länder han sido recelosos de su autonomía, lo que culturalmente ha influido en la interpretación que los diversos tribunales constitucionales (federal y local) han realizado del derecho a efecto de garantizar un pluralismo político con marcos de autonomía delimitados. Tales condiciones parecen encontrar un eco en el 
Esta revista forma parte del acervo de la Biblioteca Jurídica Virtual del Instituto de Investigaciones Jurídicas de la UNAM

escenario mexicano narrado en la primera sección de este estudio, en tanto del despertar de la justicia constitucional local se vio motivado por una búsqueda de garantía del pluralismo político intra entidades federativas, así como la aspiración a modelos funcionales de justicia constitucional. En tal tesitura, parece que la forma federal de Estado, la coexistencia de jurisdicciones constitucionales y el contexto político-jurídico ofrecen condiciones de cierta homogeneidad que posibilitan la comparación de los ordenamientos jurídicos de México y Alemania en torno a modelos de justicia constitucional local.

La jurisdicción constitucional local alemana tiene su fundamento en la autonomía de los Länder (BVerfGe, 36) y coexiste con la jurisdicción constitucional federal de forma independiente (BVerfGe, 6). Cada Land ha erigido internamente un Tribunal Constitucional.

Durante mucho tiempo, el Land Schleswig-Holstein careció de una jurisdicción constitucional propia. El Tribunal Constitucional federal hacía las veces de Tribunal Constitucional del Land en uso de la cláusula de habilitación prevista en el artículo 99 de la Ley Fundamental de Bonn (Gröpl, 2013: p. 670). A pesar de ello, la ausencia de jurisdicción propia había venido siendo un tema habitual de discusión (Lösing, 2002: 298) y a raíz de las reformas a la Constitución del Land en el año 2006, se terminó estableciendo una jurisdicción constitucional (Benda \& Klein, 2010: 19). Las razones para no adoptar una jurisdicción constitucional local fueron también coyunturales. El constituyente del Land dudaba de la viabilidad de la existencia misma de "Schleswig-Holstein" y trató de dar un ordenamiento temporal que facilitase la reconstrucción en la Alemania de la posguerra (Waack, 2008: 14).

Esto nos ofrece una perspectiva diversa de 16 Länder todos con jurisdicciones constitucionales. A diferencia de lo que ha ocurrido en México, el empleo de la justicia constitucional local en Alemania es algo habitual y presenta un número considerable de procesos, como demostró hace tiempo Heyde (1983: 2-15).

Los mecanismos de los que conoce la jurisdicción local también son variados, aunque hay rasgos comunes. Sin excepción, la justicia constitucional local conoce de controversias constitucionales (Organstreitigkeiten) y de acciones de inconstitucionalidad (Abstrakte Normenkontrolle). Algunos modelos también de cuestiones de inconstitucionalidad (Richtervorla- 
Esta revista forma parte del acervo de la Biblioteca Jurídica Virtual del Instituto de Investigaciones Jurídicas de la UNAM

gen), control electoral, amparo local (Kommunalverfassungsbeschwerde), control de referéndum y consultas populares, inter alia.

Al igual que en México, la articulación de las jurisdicciones constitucionales ha sido un tema debatido. Burmeister inclusive, sostuvo alguna vez que, en Alemania, el deslinde entre la jurisdicción local y la federal era "la cuestión fundamental menos aclarada de toda la jurisdicción constitucional" (Burmeister, 1983: 426). Empero, fuera de debates puntillosos, se ha consolidado un criterio en base al parámetro de control (Prüfungsmaßtab) con un deslinde sólido entre ambas jurisdicciones constitucionales. ${ }^{4}$

En el caso del Tribunal Constitucional Federal, el parámetro será la Constitución y normas federales. El Tribunal de Karlsruhe sólo puede utilizar el derecho de los Länder como parámetro cuando resuelva subsidiariamente los conflictos entre la Federación y los Länder o éstos entre sí en términos del artículo 93.1.4 GG. La segunda posibilidad sería, como ya mencionamos, la habilitación mediante ley al Tribunal Constitucional como Tribunal Constitucional local (artículo 99 GG). En cambio, el parámetro de control de los Tribunales locales sería la respectiva Constitución del Land y especialmente todos los derechos allí garantizados (Benda \& Klein, 2010: 22). Lo anterior no implica en su totalidad la ausencia de un potencial control, sobre todo a través del amparo contra actos de un Tribunal Constitucional local que vulneren la Constitución federal. A pesar de ello, la interpretación del Tribunal Federal ha sido restrictiva para evitar una "debilitamiento del control local".

El deslinde entre las jurisdicciones se fortalece porque no existe un control federal de los conflictos internos ni del control interno de la constitucionalidad de las normas de un Land. ${ }^{5}$ El modelo alemán parte constitucionalmente de un esquema de coordinación, donde la propia Ley Fundamental de Bonn asume la creación de jurisdicciones locales, reservando al Tribunal Constitucional Federal sólo para el caso excepcional de la ha-

4 Inclusive han llegado a darse propuestas de (con sus matices), emplear a los Tribunales Constitucionales de los Länder para aliviar la sobrecarga de trabajo producida por el amparo en el Tribunal Constitucional Federal (Schneider, 1999: p .103-11).

5 Esto fue mencionado en el debate constituyente de Nordrhein-Westfale. Se argumentó que, dado que el Tribunal Constitucional federal "no tiene competencia para todas las controversias constitucionales a nivel del Land", era conveniente la creación de un tribunal constitucional propio como forma de garantizar "un orden libre y democrático" (Johann, 2000: 56).

Cuestiones Constitucionales, Núm. 44, Enero-Junio 2021

ISSN: $2448-4881$ 
Esta revista forma parte del acervo de la Biblioteca Jurídica Virtual del Instituto de Investigaciones Jurídicas de la UNAM

bilitación (como en Schleswig-Holstein). Por tanto, el ámbito de solapamientos posible es mucho menor que en el caso mexicano.

Respecto a la configuración de los procesos, debe tenerse en cuenta que es posible apreciar una diferencia en las circunstancias de los Länder ya formados previa a la reunificación alemana en 1989 y los formados después. Los Länder posteriormente erigidos (Berlín, ${ }^{6}$ Brandenburg, Mecklenburg-Vorpommern, Sachsen, Sachsen-Anhalt y Thürigen) tuvieron opción de observar la configuración no sólo de los procesos constitucionales a nivel federal, sino también en las otras Entidades Federativas.

Resulta, por ejemplo, curioso el que los últimos Länder en incorporarse hayan preferido utilizar denominaciones más parecidas a la de Tribunal Constitucional como Verfassungsgerichtshof (Berlín, Sachsen y Thürigen), Verfassungsgerichts (Brandenburg) o Landesverfassungsgerichts (Mecklenburg-Vorpommern, Sachsen-Anhalt). Ninguno de los Länder de incorporación reciente utilizó la terminología de Tribunal de Estado (Staatsgerichtshof) presente en varios de los Länder originales (BadenWürttemberg, Bremen, Hessen y Niedersachsen) y heredera del constitucionalismo de Weimar. Ello puede poner sobre relieve la voluntad de clarificar nominalmente la naturaleza de los guardianes de la Constitución local.

\section{La legitimación en las controversias constitucionales en los Länder}

La configuración del modelo conflictual local en Alemania ha sido extremadamente similar al modelo federal. En sus diferentes formulaciones, se ha mantenido generalmente las tres características fundamentales presentes en la legitimación alemana de las Streitigkeiten. En primer lugar, la legitimación es de naturaleza constitucional. Todas las Constituciones de los Länder han configurado en sus respectivas Constituciones ${ }^{7}$ la legi-

6 La antigua Constitución de Berlín había previsto en su artículo 72 la creación de un Tribunal Constitucional propio (Staatsgerichsthof) pero por circunstancias coyunturales no se erigió hasta después de la reunificación y la nueva Constitución para Berlín (Finkelnburg, 2008: 120-126).

7 A continuación, indicamos el artículo constitucional respectivo en paréntesis después del nombre del Land. Todas las alusiones entiéndanse realizadas respecto a la Constitución del Land señalado: Baden Württemberg (artículo 68), Bayern (artículo 64), Berlín (artículo 84.2.1), Brandenburg (artículo 113.1), Bremen (artículo 140), Hamburg (artículo 65.3.2), Hessen (artículo 131); Mecklenburg-Vorpommern (artículo 53.1), Nie- 
Esta revista forma parte del acervo de la Biblioteca Jurídica Virtual del Instituto de Investigaciones Jurídicas de la UNAM

timación sin delegar esta tarea a la legislación secundaria. Esto implica también que existe un potencial blindaje a favor de la legitimación constitucional, que no puede ser reducida en la ley secundaria.

Por ejemplo, en el caso de Nordrhein-Westfalen, no se menciona en la ley secundaria la posibilidad de que otros portadores de funciones constitucionales acudan al proceso. De la naturaleza constitucional de la legitimación, se sigue que no puede haber una reducción de sujetos cuya legitimación encuentra garantía en la primacía constitucional como argumentan Heusch (2010: 665) y Haas (2006: 142). En segundo lugar, existe una cláusula abierta del listado y no así sucesivas enumeraciones a modo de numerus clausus. Se utilizan conceptos interpretativos como "órganos supremos del Estado" (obersten Staatsorgans) ${ }^{8}$ o su equivalente "órganos supremos del Land" (oberste Landesorgan) y la aún más abierta "órganos constitucionales" (como es el caso de Bremen, Hamburg y Rheinland-Pfalz). Ocasionalmente se mencionan sujetos concretos también, pero sin cerrar el listado. ${ }^{10}$ Se abre la posibilidad a que partes de estos órganos o fracciones dotadas de competencias específicas puedan utilizar las controversias constitucionales.

En los Länder de más reciente creación debe también notarse la extrema similitud entre la redacción de sus respectivos artículos, con apenas matices terminológicos. Finalmente, se ha evitado por completo el señalamiento de relaciones intersubjetivas entre los sujetos legitimados, con lo cual la litis puede entablarse entre cualquiera de ellos (sin contrastar si la relación procesal concreta se contempla en el listado).

dersachen (artículo 54.1), Nordrhein-Westfalen (artículo 75.2), Rheinland-Pfalz (artículo 130.1), Saarland (artículo 97); Sachsen (artículo 81.1.1), Sachsen-Anhalt (artículo 75.1), Schleswig-Holstein (artículo 44.2.1) y Thüringen (artículo 80.3).

8 Es el caso de Bayern y Sachsen.

9 Es el caso de Baden-Württemberg, Berlín, Brandenburg, Mecklenburg-Vorpommern, Niedersachen, Nordrhein-Westfalen, Saarland, Sachsen-Anhalt y Thürigen. Cabe resaltar que los respectivos Tribunales de los Länder calificarían, en su caso, como órganos constitucionales u órganos supremos del Land pero, al igual que en el modelo federal, han sido excluidos del conflicto. En el caso de Thüringen lo afirma Jutzi (2013: 901).

10 Así es el caso de Schleswig-Holstein que menciona concretamente al Parlamento y al Gobierno. Nótese que esta mención es distinta a la hecha con los "portadores de funciones constitucionales" hecha en las demás constituciones, en tanto aquí es una mención autónoma y no una alusión a las partes de aquéllos órganos dotados con funciones propias.

Cuestiones Constitucionales, Núm. 44, Enero-Junio 2021

ISSN: $2448-4881$ 
Esta revista forma parte del acervo de la Biblioteca Jurídica Virtual del Instituto de Investigaciones Jurídicas de la UNAM

Como resultado de la configuración anteriormente señalada, tenemos que las controversias constitucionales han sido usuales a nivel local, inclusive en los Länder de reciente creación. ${ }^{11}$ La interpretación de los Tribunales Constitucionales locales ha sido congruente permitiendo grados de flexibilidad similares al modelo federal.

Los casos prototípicos de sujetos legitimados son el Parlamento y el Gobierno del Land, como el caso de Sachsen-Anhalt (Halle, 2004: 482). La interpretación de la cláusula abierta ha sido concretada ${ }^{12}$ por la interpretación entre otros sujetos, en el Presidente del Landtag, fracciones parlamentarias, minorías en defensa de los derechos del Parlamento (Haas, 2006: 147), diputados uti singuli, al Ältestenrat (comité parlamentario que, entre otras cosas, determina el orden del día), minorías en Comisiones de Investigación, Comités Parlamentarios, ${ }^{13}$ Presidente del Land,${ }^{14}$ Ministros del Land con funciones propias (Heusch, 2010: 655), Comité para el Referéndum, los partidos políticos cuando defienden su especial posición en

\footnotetext{
11 Respecto al caso de Mecklenburg-Vorpommern, así lo afirma Hückstädt (2008: 142).

12 También, al igual que en el modelo federal, las leyes de los respectivos Tribunales Constitucionales han consagrado concretamente algunos sujetos. Remitimos al lector a ellas, entendiendo que las siguientes alusiones son hechas respecto a la ley del Tribunal Constitucional del Land respectivo: Baden-Württemberg (artículo 44), Bayern (artículo 48), Berlín (artículos 14 y 36), Brandenburg (artículos 12 y 35), Bremen (artículo 24), Hamburg (artículo 39 a), Hessen (artículo 42.2), Mecklenburg-Vorpommern (artículos 11.1 y 36), Niedersachsen (artículos 8.6 y 30), Nordrhein-Westfalen (artículo 43), Rheinland-Pfalz (artículo 23), Saarland (artículos 9 y 39), Sachsen (artículo 17), Sachsen-Anhalt (artículo 35), Schleswig-Holstein (artículo 35) y Thüringen (artículos 11.3 y 38).

13 Contrástese con la interpretación del Staatsgerichsthof de Niedersachen en (Hüpper, 2000: 179) y del Verfassungsgerichsthof de Nordrhein-Westfalen por Pieroth (2002: 107-109).

14 Este caso es común en tanto las diversas constituciones le establecen competencias directamente atribuibles. En el caso de Thüringen, la competencia de nombrar y remover funcionarios (artículo 78.1 de la Constitución). Así también lo afirma Müller (2005: 201).
} 
Esta revista forma parte del acervo de la Biblioteca Jurídica Virtual del Instituto de Investigaciones Jurídicas de la UNAM

la estructura constitucional, ${ }^{15}$ etcétera. ${ }^{16}$ También se han producido debates en torno a otros sujetos como los tribunales de cuentas. ${ }^{17}$

\section{La legitimación en la acción de inconstitucionalidad en los Länder}

Las acciones de inconstitucionalidad, lógicamente, han tenido un tratamiento mucho más modesto en materia de legitimación. Sin embargo, el hecho de que no haya un control federal sobre la constitucionalidad local de las normas a instancias de minorías locales ha hecho que la importancia de estos procesos se resalte. En Alemania, las minorías parlamentarias ejercen en las acciones locales un control único, no optativo. Es decir, en Alemania, las minorías parlamentarias sólo pueden cuestionar la constitucionalidad de leyes en vía local y no pueden elegir entre la vía local o federal, como sí ocurre en algunos casos en México.

Fuera de las consideraciones mencionadas, la configuración de las acciones de inconstitucionalidad ha sido, al igual que en las controversias, relativamente similar al modelo federal, con puntuales variaciones. A nivel general se han mantenido también (salvo puntuales excepciones) las tres características de la legitimación en el control abstracto alemán: a) naturaleza constitucional, b) legitimación taxativa o numerus clausus, lo que

15 Aunque, al igual que a nivel federal, esto se ha hecho tras largo debate. A modo de ejemplo, el Verfassungsgerichsthof de Nordrhein-Westfalen, inicialmente negó la legitimación a los partidos políticos, para luego afirmarla haciendo copiosas referencias a las decisiones del Tribunal Constitucional federal y argumentando que los partidos políticos desempeñaban funciones de órganos constitucionales (Pieroth, 2002: 109). Una respuesta también afirmativa en Rheinland-Pfalz (Jutzi, 2005: 140) y Thüringen.

16 Un caso especial es Hessen, en tanto no menciona en su Constitución (artículo 131) una categoría abierta de sujetos legitimados, haciendo simple referencia a que el Tribunal Constitucional del Land conocerá de las controversias respectivas. Se menciona concretamente al Landtag, una fracción del Landtag, el Gobierno del Land, el presidente del gobierno y el Tribunal de Cuentas en lo correspondiente a su participación en los presupuestos estatales y opinión sobre la deuda del Land (artículo 144 de la Constitución de Hessen). Será posteriormente la Ley sobre el Tribunal Constitucional de Hessen (artículo 41.1) la que haga alusión a la clásica fórmula abierta (Hecker: 2002: 447).

17 Como en Rheinland-Pfalz (Jutzi, 2005: 141) y Thüringen "dado que las competencias y posición del Tribunal de Cuentas se establecen en la Constitución y el artículo 80.1.3 no supedita la facultad de ser parte a la de ostentar la calidad de órgano constitucional el Tribunal de Cuentas tiene la capacidad de ser parte...” (Jutzi, 2013: 902).

Cuestiones Constitucionales, Núm. 44, Enero-Junio 2021

ISSN: $2448-4881$ 
Esta revista forma parte del acervo de la Biblioteca Jurídica Virtual del Instituto de Investigaciones Jurídicas de la UNAM

impide ampliar el número de sujetos legitimados (Haas, 2006: 157) y, c) naturaleza institucional de los sujetos legitimados.

En primer lugar, todas las constituciones de los Länder han previsto, a su vez, la legitimación para la acción de inconstitucionalidad, con lo cual esta legitimación dimana de la Constitución ${ }^{18}$ y no de normas secundarias. En segundo lugar, a diferencia de los conflictos constitucionales, los modelos han acudido a un numerus clausus, expresando taxativamente a los sujetos con capacidad para iniciar el procedimiento. Finalmente, en la mayoría de los casos la legitimación ha sido de naturaleza institucional, en tanto sólo sujetos institucionales (minorías parlamentarias y Gobierno del Land) han sido dotados de legitimación.

Es debatible si pudiese considerarse una pequeña excepción la legitimación que Bremen y Rheinland-Pfalz (artículos 140 y 130 constitucionales, respectivamente) consagran a favor de una "corporación pública del Estado" (öffentlich-rechtliche Körperschaft), en tanto que la categoría debe individualizarse y ha llegado a incluir sujetos fuera del Estado-aparato. Sobre ello, Rinken afirma "Notable es, por otro lado, la apertura de las corporaciones públicas de Bremen a todos los procedimientos constitucionales, explicable sólo desde la tradición Hanseática" (Rinken, 1991: 502). Con esta legitimación, prosigue Rinken, no sólo se ha logrado darle acceso al Tribunal a las ciudades de Bremen y Bremenharven - especie de control normativo comunal o amparo local - sino incluso a todas las corporaciones públicas.

Nótese que la interpretación del Tribunal de Bremen (Rinken, 1991: 503), siempre ha ligado la legitimación de las corporaciones públicas con un ámbito competencial propio. Entre las corporaciones públicas que se han legitimado se encuentra el colegio de abogados, la Iglesia Evangélica de Bremen y dos parroquias católicas (éstas últimas dos tienen una reminiscencia fuerte del constitucionalismo de Weimar). En cambio, a pesar de que Rheinland-Pfalz tiene la misma legitimación, no ha considerado legitimadas a las asociaciones religiosas (Religionsgemeinschaften) pues

18 Nuevamente, señalamos el Land y entre paréntesis el artículo respectivo de su Constitución: Baden-Württemberg (artículo 68.2), Berlín (artículo 84.2.2), Brandenburg (artículo 113.2), Bremen (artículo 140), Hamburg (artículo 65.3.3), Hessen (artículo 131.2); Mecklenburg-Vorpommern (artículo 53.2), Niedersachen (artículo 54.3), Nordrhein-Westfalen (artículo 75.3), Rheinland-Pfalz (artículo 130.1), Saarland (artículo 97.2); Sachsen (artículo 81.1.2), Sachsen-Anhalt (artículo 75.3), Schleswig-Holstein (artículo 44.2.2) y Thüringen (artículo 80.1.4). 
Esta revista forma parte del acervo de la Biblioteca Jurídica Virtual del Instituto de Investigaciones Jurídicas de la UNAM

se ha sostenido que a pesar de su estatus público-jurídico son corporaciones "sui generis no integradas en el Estado-aparato" (Jutzi, 2013: 140).

Una excepción a la naturaleza constitucional lo constituye la curiosa legitimación popular (Popularklage) presente en el Land de Baviera. En Bayern (artículo 98, Constitución de Bayern) existe una "actio popularis", que es independiente de afectación o interés directo del solicitante. Linder (2011: 183) califica a la Popularklage de Bayern como "el más espectacular procedimiento en el derecho procesal constitucional alemán".

Resulta curioso que, como han apuntado Linder (2011: 183) y Bohn (2010: 83), no se haya hecho un uso excesivo del procedimiento ni se haya inundado al Tribunal con demandas temerarias. Ello se debe a varias razones. En primer lugar, la población de Bayern no es excesivamente elevada (aproximadamente 12 millones de habitantes). En segundo lugar, el parámetro de la demanda es sólo el derecho del Land, lo cual limita considerablemente las impugnaciones al parámetro local, pues no son invocables infracciones a la Constitución federal. Finalmente, el artículo 27.1 de la Ley del Tribunal Constitucional local dispone que, aunque el procedimiento ante el Tribunal es gratuito, el Tribunal puede imponer un pago de hasta 1500 euros en el caso de demandas notoriamente inadmisibles o manifiestamente infundadas (Bohn, 2010: 224).

Con la excepción antes mencionada, el procedimiento es gratuito y no se requiere representación procesal para su interposición. Desde 1947 al 2010, se tiene un promedio de 20 procedimientos por año (un total aproximado de 1300 procedimientos), con una tasa de éxito de 11\% (Jutzi, 2013: 140). Debe, empero, tenerse en cuenta que el establecimiento de la acción popular en Bayern tiene causas coyunturales concretas (Bohn, 2010: 69) sin las cuales probablemente no habría sido estatuido y es una verdadera excepción en el modelo de justicia constitucional local alemán. También resulta una excepción a la institucionalidad la legitimación que Hesse hace de un grupo correspondiente al 1\% de los electores (Constitución de Hesse, artículo 131.2).

Habiendo señalado las características de la legitimación en los modelos locales, podemos también apuntar que a nivel local se han mantenido, cuando menos, los mismos sujetos que a nivel federal, es decir, Gobierno del Land y minorías parlamentarias. ${ }^{19}$

19 Este es el caso de Baden-Württemberg, Berlín, Brandenburg, Bremen, Hamburg, Hessen, Mecklenburg-Vorpommern, Niedersachsen, Nordrhein-Westfalen, RheinlandCuestiones Constitucionales, Núm. 44, Enero-Junio 2021

ISSN: $2448-4881$ 
Esta revista forma parte del acervo de la Biblioteca Jurídica Virtual del Instituto de Investigaciones Jurídicas de la UNAM

Sobre la legitimación del Gobierno del Land no hay un gran debate fuera de su utilidad en modelos parlamentarios donde mayoría parlamentaria y Gobierno frecuentemente coinciden. Por ello, la acción tiene mayor uso como instrumento de la oposición (Heusch, 2010: 664). Sin embargo, en situaciones coyunturales puede presentar cierta utilidad. Por último, en este tema, puede señalarse que, en el caso de la legitimación del Landesreigierung, se trata de una legitimación conjunta y no se encuentran legitimados individualmente ni el presidente del Gobierno, ni los ministros (Ha1le, 2004: 483) a menos que esté expresamente estipulada tal legitimación, como en el caso de Hessen (artículo 131 constitucional y artículo 19 de la Ley sobre el Tribunal Constitucional).

Mayor interés presenta la configuración de las minorías parlamentarias. En la legitimación minoritaria de los Länder, se ha utilizado siempre el método porcentual y no el numérico directo. Los porcentajes sí han presentado, en cambio, variaciones de interés respecto al modelo federal alemán. A pesar de que ha habido algunas Entidades Federativas que han conservado el antiguo tercio del modelo federal ${ }^{20}$ la gran mayoría han previsto porcentajes menores.

Algunos Länder optaron por establecer porcentajes menores análogos al modo federal equivalentes $25 \% ;{ }^{21}$ otros establecieron porcentajes menores como el $20 \%{ }^{22}$ o el generosísimo $10 \%$ de Hessen. Inclusive, los Länder de Rheinland-Pfalz, ${ }^{23}$ Thüringen y Hessen, simplemente legitiman a cada fracción del Parlamento local (artículo 130.1, Constitución de

Pfalz, Saarland, Sachsen, Sachsen-Anhalt, Schleswig-Holstein y Thüringen. En Bayern la concreción de la legitimación es innecesaria dada la actio popularis.

20 Concretamente Mecklenburg-Vorpommern, Nordrhein-Westfalen, Saarland y Schleswig-Holstein. Recuérdese que, anteriormente, la legitimación en Alemania era de un tercio del cuerpo legislativo hasta la reforma constitucional de 2008 (Benda \& Klein, 2010: 278).

21 Legitimación análoga a la del modelo federal tras la reforma constitucional del año 2008. Estas entidades son Baden-Württemberg, Berlín, Sachsen y Sachsen-Anhalt.

22 Concretamente Brandenburg, Bremen, Hamburg, Niedersachsen y Thüringen.

23 Debe notarse lo especial que resulta el caso de Rheinland-Pfalz, en tanto la legitimación que dispone para la controversia constitucional es igualmente considerada legitimación para la acción constitucional (Jutzi, 2013: 146). 
Esta revista forma parte del acervo de la Biblioteca Jurídica Virtual del Instituto de Investigaciones Jurídicas de la UNAM

Rheinland-Pfalz, ${ }^{24}$ artículo 80.1.4 Constitución de Thüringen ${ }^{25}$ y artículo 19 de la Gesetz über den Staatsgerichsthof de Hessen). Algo similar aunque agravado - prevé Schleswig-Holstein que además de legitimar a 1/3 del Parlamento, también establece la legitimación de dos grupos parlamentarios.

De tal suerte, tomando en cuenta que la reforma constitucional federal que estableció la legitimación de $1 / 4$ es de 2008 , tenemos que el $75 \%$ de los Länder habían establecido legitimaciones menores que las del modelo federal. Se aprecia así el ánimo de las Entidades Federativas de garantizar el acceso a la justicia constitucional a minorías de entidad más limitada que las del modelo federal.

Finalmente, además de los sujetos típicos, algunos Länder han establecido legitimaciones propias dignas de mención como por ejemplo la actio popularis (Popularklage) a la que hemos hecho mención en Bayern. También interesante resulta la legitimación que se ha hecho en Hessen de una centésima parte del cuerpo electoral para la presentación de acciones de inconstitucionalidad. ${ }^{26}$

\section{Breves notas de un balance prospectivo}

Después de haber analizado someramente los modelos de legitimación local en acciones de inconstitucionalidad y controversias constitucionales en Alemania, podemos encontrar algunos rasgos que han hecho que el sistema tenga una efectividad aceptable.

24 Para determinar el número concreto debemos acudir al reglamento del Parlamento local (Geschäftsordnung des Landtags) que prevé en su artículo 8 la creación de fracciones. Sin embargo, en tal reglamento no se requiere un número mínimo de diputados al disponerse escuetamente (artículo 8) que "Los diputados elegidos al Parlamento, que pertenezcan a un mismo partido político, pueden formar un grupo parlamentario". Con lo cual, la legitimación se reduce, prácticamente, a la obtención de dos diputados en las elecciones locales.

25 En el caso de Thüringen, su reglamento Parlamentario-Geschäftsordnung des Thüringer Landtags- (artículo 8) dispone que para formar una fracción se requiere que los parlamentarios a ella pertenecientes equivalgan al 5\% del número de parlamentarios integrantes del Landtag, lo que nos da un promedio de 4.4 parlamentarios.

26 Lo que se traduce aproximadamente en 60,000 electores, tomando en cuenta que la población de Hesse excede por poco los seis millones de habitantes.

Cuestiones Constitucionales, Núm. 44, Enero-Junio 2021

ISSN: $2448-4881$ 
Esta revista forma parte del acervo de la Biblioteca Jurídica Virtual del Instituto de Investigaciones Jurídicas de la UNAM

En primer lugar, ha sido la propia Constitución la que preveía la posible existencia de estas jurisdicciones constitucionales y disponía el conocimiento por el Tribunal Constitucional federal de ciertas controversias sólo en el caso de la mencionada cláusula de habilitación del artículo 99. En segundo lugar y por consecuencia, el Tribunal Constitucional no funge naturalmente como garante de la Constitución de los Länder, con lo cual la vía local no se convierte en optativa sino en obligatoria previo, en su caso, al Tribunal Constitucional federal. Es decir, existe un principio de subsidiariedad.

En tercer lugar, a pesar de que las Entidades Federativas, en general, han seguido el modelo federal, se aprecia una tendencia a facilitar el acceso a la jurisdicción constitucional sea ya con la introducción de nuevos sujetos legitimados o con la reducción de los requisitos a los sujetos clásicos (menores porcentajes a las minorías parlamentarias, legitimación de grupos parlamentarios autónomamente, etcétera).

\section{LA LEGITIMACIÓN EN LAS CONTROVERSIAS CONSTITUCIONALES LOCALES EN MÉXICO}

\section{La duplicidad como regla}

En el caso de los procesos locales, la duplicidad se ha dado como regla general en los procesos de defensa competencial similares a los modelos remotos en la Constitución mexicana (Figueroa, 2013, 230). Diversas Entidades Federativas han establecido una legitimación totalmente coincidente con el nivel federal. Guerrero es una buena muestra, al establecer que el Tribunal Superior de Justicia resolverá los conflictos "entre los Municipios y el Gobierno del Estado". Otros estados, como el propio Veracruz, han ampliado un poco más el modelo, permitiendo que los conflictos se susciten también entre "El Poder Ejecutivo y el Legislativo". Ambos casos, son muestras de legitimaciones restrictivas que limitan al máximo la posibilidad del planteamiento de conflictos alternativos.

En general, las fórmulas de legitimación que se han empleado han sido cerradas, tasadas y con ausencia de fórmulas interpretativas. Este es el caso de Guerrero, Veracruz, Chiapas, Tlaxcala, Guanajuato, Estado de 
Esta revista forma parte del acervo de la Biblioteca Jurídica Virtual del Instituto de Investigaciones Jurídicas de la UNAM

México, Quintana Roo, Chihuahua (con cláusula inhibitoria ${ }^{27}$ en lo coincidente con la jurisdicción federal), Coahuila (con la excepción que se señalará), Colima (con cláusula inhibitoria), Chihuahua (con cláusula inhibitoria), Hidalgo, Zacatecas (con cláusula inhibitoria), Tlaxcala y Tabasco. A pesar de que Tabasco hace alusión a la expresión genérica de "Poderes del Estado", esta terminología se encuentra limitada. La Constitución tabasqueña alude a conflictos entre "los Municipios y cualquiera de los otros dos Poderes del Estado". Ello implica un reenvío al esquema trinitario, por lo cual categorizamos tal legitimación como restrictiva. Sin embargo, la terminología despierta dudas. Si se sostiene que los conflictos podrán presentarse entre "los Municipios y cualquier otro de los otros dos Poderes del Estado" ¿se está tomando al municipio como parte integrante del esquema trinitario? y ¿cuáles serían los dos Poderes del Estado restantes? Independientemente de la respuesta, se excluirá a alguno de los tres actores del esquema clásico.

Estos Estados, que han optado por fórmulas restrictivas análogas a la federal, se encuentran con una desesperanzadora perspectiva. En el estado actual, difícilmente encontrarán conflictos que no puedan ser planteados ante la jurisdicción federal. La ausencia ulterior de sujetos legitimados no ofrece mayores posibilidades. En estos casos, la lista cerrada y tasada, así como la eventual previsión de relaciones subjetivas cumplirán un papel inhibitorio de la jurisdicción local. Excepciones puntuales las constituyen legitimaciones no coincidentes, como el caso de los munícipes en Tlaxcala.

\section{Legitimación tasada pero inclusiva}

Otra serie más reducida de modelos ha mantenido la lista cerrada y tasada, pero ha ampliado significativamente la lista de sujetos legitimados para entablar las controversias locales. A este sector pertenecen Coahuila (entidades paraestatales, paramunicipales y organismos públicos autónomos); Ciudad de México (organismos constitucionales autónomos y concejo); ${ }^{28}$ Sonora (entidades paramunicipales y paraestatales); Naya-

27 Por cláusula inhibitoria designo a la autoexclusión realizada en las Constituciones o leyes locales, del conocimiento de asuntos competencia del modelo federal de control constitucional.

28 Ciudad de México ha previsto una hipótesis peculiar en que existe la posibilidad Cuestiones Constitucionales, Núm. 44, Enero-Junio 2021

ISSN: $2448-4881$ 
Esta revista forma parte del acervo de la Biblioteca Jurídica Virtual del Instituto de Investigaciones Jurídicas de la UNAM

rit (organismos autónomos); Oaxaca (órganos autónomos); Campeche (paraestatales, paramunicipales) ${ }^{29}$ y Morelos (Universidad Autónoma de Morelos)..$^{30}$

Los modelos anteriores pueden ser considerados relevantes como antecedente, pues la legitimación local otorgada a los "órganos constitucionales autónomos" precede a la reforma federal que los legitimó en el $2014^{31}$. Es decir, tenemos un claro caso en que la Federación reconoce tácitamente por la vía de la reforma constitucional la idoneidad de modelos de justicia constitucional local, aunque no hay evidencia empírica suficiente de su funcionamiento.

\section{Las fórmulas abiertas}

Fuera de los modelos anteriormente mencionados, existen Entidades Federativas que han optado por legitimaciones abiertas, sea ya utilizando conceptos interpretativos de forma voluntaria o evitando la enumeración tasada de sujetos. Por ejemplo, el artículo 96 de la Constitución Política de Durango dispone que el Tribunal Superior de Justicia resolverá "los conflictos que surjan entre los ayuntamientos y los poderes del Estado".

Una fórmula similar emplea Sinaloa al disponer en su Constitución que el Tribunal Superior resolverá los conflictos "entre los Poderes del Estado" (artículo 104), opción terminológica que también emplea la Constitución de Querétaro (artículo 70, con cláusula inhibitoria). Morelos también debe

de plantear un conflicto entre la persona titular de una Alcaldía y el Concejo de ésta (artículo 36, base $\mathrm{C}$, numeral 2, inciso a).

29 Resulta sumamente curioso que Campeche considere como sujetos legitimados a entidades Paraestatales y Paramunicipales y, en cambio, no otorgue legitimación a órganos constitucionales autónomos locales con mayores grados de autonomía.

30 Como se hará alusión con posterioridad, Morelos es un modelo mixto. Emplea un concepto abierto "órgano estatal regulado por esta Constitución", pero al mismo tiempo hace enumeración de varios sujetos como el Instituto Estatal Electoral y la Universidad Autónoma de Morelos. La diferencia estriba en que, de los dos sujetos mencionados, la Universidad no se subsumiría en el concepto de "órgano regulado por esta Constitución" como sí lo hace el Instituto Electoral. Por tal medida, consideramos que Morelos tiene, en su faceta de lista, la legitimación ulterior de su Universidad Autónoma.

31 Además, recuérdese que la actual interpretación de la Suprema Corte mexicana no permite que órganos constitucionales autónomos acudan a la controversia constitucional. Véase los recursos de reclamación 76/2016-CA y 28/2015-CA, resueltos por la Suprema Corte. 
Esta revista forma parte del acervo de la Biblioteca Jurídica Virtual del Instituto de Investigaciones Jurídicas de la UNAM

considerarse poseedor de una fórmula abierta. La legitimación en los conflictos internos en Morelos prevé sujetos como el Instituto Morelense de Información Pública y Estadística, el Instituto Estatal Electoral y su Universidad Autónoma. Sin embargo, más adelante es el propio texto constitucional el que permite que sea parte de estas controversias "cualquier órgano estatal regulado" por la Constitución ${ }^{32}$.

En esta tesitura, es posible detectar dos modelos distintos de legitimación abierta. Por un lado, se encuentran aquellas Entidades Federativas (Querétaro, Durango y Sinaloa) que han optado por emplear la terminología italiana de "Poderes del Estado". Por otro lado, se encuentra la original legitimación de Morelos que, a pesar de hacer uso de un listado puntilloso, termina remitiendo al generosísimo concepto de "órgano estatal" para efectos de legitimación. La misma legitimación "poderes u órganos públicos estatales o municipales" está presente en la Constitución de Nuevo León (artículo 95), Sonora con "organismos públicos autónomos" (artículo 166, fracción I, inciso h) y en la de Yucatán, que alude a "órganos de gobierno" (artículo 70.I).

En el primer caso, tenemos que el alcance del término "Poder del Estado" puede ser interpretado y discutido al modo italiano ${ }^{33}$. El camino está abierto a potenciales interpretaciones garantistas. A pesar de la inexistencia formal de una cláusula que se refiera a fracciones que "expresen definitivamente la voluntad" de un Poder del Estado, habrá ocasiones en que sea lógico asumir que tales fracciones podrían utilizar la vía local. Por ejemplo, la función de las Comisiones legislativas locales a la luz de sus competencias reglamentarias o la instalación de comisiones de investigación a petición de una minoría. En estos casos, podemos sostener que, a pesar de no ser el órgano plenario, una minoría puede expresar defini-

32 Nótese que, en ausencia de mención específica, el Instituto Morelense de Información Pública y Estadística sí podría ser un sujeto legitimado. No así en cambio la Universidad Autónoma de Morelos, que, como se ha señalado en la sección correspondiente, no es un órgano constitucional autónomo ni cumple funciones del Estado-aparato. Ello nos lleva a pensar que la mención de la Universidad como sujeto legitimado es significativa en tanto este sujeto no es, a su vez, subsumible en el concepto interpretativo utilizado posteriormente.

33 En Italia, el conflicto entre poderes del Estado emplea la terminología "poteri dello Stato". Ello ha abierto un fuerte debate en que ha sido posible expandir la legitimación interpretando qué órgano puede representar la voluntad del Estado en un momento determinado como muestran Mazziotti (1972: 109) y Bettinelli (1993: 5).

Cuestiones Constitucionales, Núm. 44, Enero-Junio 2021

ISSN: $2448-4881$ 
Esta revista forma parte del acervo de la Biblioteca Jurídica Virtual del Instituto de Investigaciones Jurídicas de la UNAM

tivamente la voluntad de la Cámara y, por lo tanto, del Poder del Estado correspondiente.

La interpretación podría llevarse más lejos ¿no es sostenible que una fracción del cuerpo electoral sí represente a estos efectos un Poder del Estado cuando se le ha dado competencias en el proceso legislativo en la forma de una iniciativa legislativa popular ${ }^{34}$ ? Asimismo, la expresión "poderes", en ausencia de toda connotación triádica, permite también considerar como tales a los órganos constitucionales autónomos de las Entidades Federativas, como por ejemplo las Comisiones de Derechos Humanos. A pesar de que aún no existe material para realizar una valoración empírica del comportamiento de este modelo, las posibilidades interpretativas son naturalmente mayores que en el modelo federal de lista cerrada y tasada. La doctrina italiana bien podría servir de guía inicial en la interpretación del concepto "Poderes del Estado".

El segundo caso (Morelos, Yucatán y Nuevo León) ofrece igualmente amplias posibilidades, pues requiere para la legitimación la condición propia de órgano en la Constitución estatal. De tal suerte, a la luz de este criterio, es indudable que tendríamos la legitimación arquetípica del Gobernador del Estado -poder ejecutivo- y el Congreso Local -poder legislativo-. Pero de igual modo, calificarían como órganos el Consejo Estatal de Participación Ciudadana, la Comisión local de Derechos Humanos, el Instituto Estatal Electoral, Paraestatales, etc. Es decir, no sólo los órganos constitucionales autónomos podrían potencialmente tener acceso al mecanismo, sino inclusive órganos propios enmarcados en sí dentro de la dinámica jerárquica de los poderes clásicos.

\section{LA LEGITIMACIÓN EN LAS ACCIONES DE INCONSTITUCIONALIDAD EN LAS ENTIDADES FEDERATIVAS}

\section{La legitimación del ejecutivo}

Si el ejecutivo se ha concebido como un sujeto frecuentemente legitimado, las Entidades Federativas darán respuestas distintas a su legitimación, sea ya en la forma (sujeto legitimado) o en la sustancia, llegando inclusive a privarlo de ella. Empero, a este respecto, creemos que la le-

34 Por ejemplo, el artículo 18.6 de la Constitución del Estado de Querétaro. 
Esta revista forma parte del acervo de la Biblioteca Jurídica Virtual del Instituto de Investigaciones Jurídicas de la UNAM

gitimación del ejecutivo estatal puede ser útil ante la posibilidad de un ejecutivo con minorías legislativas ${ }^{35}$.

Dejando fuera los controversiales aspectos de la articulación de jurisdicciones, podemos observar que, si bien las minorías políticas conservan legitimación para acudir a la Suprema Corte (artículo 105, II, d, CPEUM) no tiene así esta facultad el ejecutivo de las Entidades Federativas. De tal suerte, en los ordenamientos que a continuación se siguen, encontramos un sujeto legitimado ex novo respecto a la Constitución federal.

\section{A. La legitimación sin ambages: El gobernador del Estado}

Anteriormente he sostenido que, en el modelo federal la legitimación del procurador de la República era una vía indirecta de legitimación de Presidencia de la República con una desviación de responsabilidad (Rivera, 2016: 240). Algunos estados habían considerado que la anterior vía indirecta es innecesaria y han consagrado sin ambages una legitimación para el titular del poder ejecutivo. Se ha así innovado sobre el modelo federal porque esta legitimación directa se encontraba establecida previa a la reforma constitucional de 2014 y previo a la entrada en vigor de tal reforma en diciembre de 2018.

Las entidades que directamente otorgan legitimación al ejecutivo estatal son, con sus variaciones terminológicas, ${ }^{36}$ Veracruz, Chiapas, Tlaxcala

35 Claro que tal posibilidad podría ser llevada a cabo en la actualidad mediante la controversia constitucional (por ejemplo, impugnando una norma de carácter general), pero la discusión debería versar exclusivamente sobre ámbitos competenciales y no una impugnación de carácter "libre" propia de la acción abstracta de inconstitucionalidad.

36 La forma de consagrar dicha legitimación oscila en torno a dos grandes modelos. La expresión directa "Gobernador del Estado" ha sido empleada por Veracruz, Chiapas, Tlaxcala, Estado de México y Oaxaca. Por otro lado, Yucatán y Coahuila han favorecido la expresión "Ejecutivo del Estado" sin que esta elección tenga alguna incidencia real sobre la configuración de la legitimación. Vale la pena apuntalar que Coahuila ha constitucionalizado (artículo 158. I. a) la posibilidad de que el ejecutivo la interponga por sí o por conducto de quien legalmente lo represente. Tal consagración parece ser una respuesta directa a la exigencia citada en el III párrafo del artículo 11 de la Ley Reglamentaria de las Fracciones I y II del artículo 105 CPEUM que podría llevarnos a pensar que la representación, per se, es un requisito para la presentación de la demanda. Coahuila ha zanjado la discusión en este aspecto al textualmente dejar en claro que la representación es innecesaria para la presentación de la demanda.

Cuestiones Constitucionales, Núm. 44, Enero-Junio 2021

ISSN: $2448-4881$ 
Esta revista forma parte del acervo de la Biblioteca Jurídica Virtual del Instituto de Investigaciones Jurídicas de la UNAM

(acotando el objeto a normas municipales, pero no del Estado), ${ }^{37}$ Estado de México, Coahuila, Oaxaca, Ciudad de México, ${ }^{38}$ Sonora $^{39}$ y Yucatán. Con ello no pretendemos sostener que otras Entidades Federativas no contemplen la legitimación indirecta a modo en que anteriormente lo hacía la Constitución federal, punto que será discutido en la siguiente sección.

Pareciera que tal legitimación directa volvería innecesaria la legitimación del Procurador del Estado, pero esto no ha sido siempre así. En efecto, Veracruz, Estado de México, Coahuila y Oaxaca no han visto razones para conceder legitimación al Procurador de la Entidad si ya el ejecutivo es titular de una facultad directa de impugnación. Sin embargo, Chiapas, Sonora (con acotación a la materia penal), Yucatán y Tlaxcala han mantenido la dualidad de sujetos legitimados, coexistiendo la legitimación del Gobernador del Estado con la del propio Procurador.

Chiapas ha acotado ligeramente la facultad de impugnación del Procurador General del Estado a normas expedidas por el Congreso Local. Lo propio ha hecho Coahuila (reforma de 2017) que ha acotado la impugnación a materia penal y procesal penal), mientras que Yucatán ha mantenido irrestricta esta capacidad a su "Fiscal General". Curioso es el caso de Tlaxcala (al que tendremos ocasión de referirnos en la sección siguiente) que mantiene legitimación al Procurador "en lo relativo a su función". Esta cláusula puede tener una interpretación más amplia que la limitación federal correlativa a normas procesales penales. Lo relativo a la función del Procurador puede implicar también reivindicación de competencias propias.

Como una valoración general de la configuración directa, podemos establecer que ha sido adecuada (la coexistencia de legitimaciones como en el caso de Tlaxcala no es imputable a la configuración singular del ejecutivo) y es bastante clara respecto a su finalidad. Como se ha sostenido previamente, esta legitimación fortalece al ejecutivo y puede utilizarla

37 Respecto de normas emitidas por el Congreso del Estado, sigue teniendo legitimación el Procurador General de Justicia del Estado, acotado a los asuntos relativos a su función (Constitución de Tlaxcala, artículo 81, fracción III, inciso d).

38 Por la peculiar denominación en el caso de Ciudad de México, naturalmente la legitimación se consagró a favor de "La o el jefe de gobierno" (artículo 36, base C, numeral 1, inciso a).

39 Sonora emplea la formulación abstracta "El Ejecutivo del Estado por sí o por conducto de quien lo represente legalmente". 
Esta revista forma parte del acervo de la Biblioteca Jurídica Virtual del Instituto de Investigaciones Jurídicas de la UNAM

como herramienta de control y contrapeso cuando se encuentra en un Congreso local dominado por fuerzas políticas adversas.

\section{B. La vía indirecta y el juego de las acotaciones:} El Procurador de Justicia

A pesar del carácter innovador de la legitimación directa del ejecutivo al que hemos hecho referencia anteriormente, otras Entidades Federativas han juzgado conveniente mantener el modelo federal que existía previo a la reforma de 2014 y lo han reproducido en mayor o menor medida con sus giros terminológicos. ${ }^{40}$

Chiapas, Quintana Roo (contra normas estatales), Nayarit, Nuevo León, Yucatán y Tlaxcala han mantenido la legitimación del Procurador/Fiscal General en la acción de inconstitucionalidad. Sin embargo, de estas Entidades Federativas, como ya se ha mencionado, Chiapas, Ciudad de México, Yucatán y Tlaxcala han legitimado también directamente al ejecutivo de la Entidad Federativa. Podemos así constatar que, al no tener una finalidad indirecta de legitimación al ejecutivo, la legitimación del procurador en tales entidades federativas debe necesariamente conceptualizarse como correspondiente a otra finalidad más tutelar de la función propia que de la constitucionalidad general. Lejos está cualquier procurador de una entidad federativa de ser aquel defensor abstracto con fuertes garantías de independencia que Kelsen (2001: 90) planteaba como potencial titular de una facultad genérica de impugnación.

Por ello podemos propiamente hablar de dos grandes grupos de legitimación procesal constitucional local del procurador de la entidad federativa. Por un lado, el modelo indirecto (a semejanza de la Constitución federal antes de la reforma), se encuentra conformado exclusivamente por Nayarit, Nuevo León y Quintana Roo. En el modelo indirecto, pueden reproducirse las consideraciones sobre responsabilidad política derivada que resultan aplicables al modelo federal.

En el segundo modelo, tenemos las entidades de Chiapas, Ciudad de México, Yucatán y Tlaxcala cuya dualidad de legitimaciones parece pretender fomentar el uso de los mecanismos de control constitucional local

40 Es decir, se emplea ocasionalmente la denominación fiscal general, como Yucatán, u ocasionalmente se mantiene la antigua de procurador general, como en Nuevo León.

Cuestiones Constitucionales, Núm. 44, Enero-Junio 2021

ISSN: $2448-4881$ 
Esta revista forma parte del acervo de la Biblioteca Jurídica Virtual del Instituto de Investigaciones Jurídicas de la UNAM

al posibilitar que un mayor número de actores tengan acceso a tales mecanismos. Yucatán y Ciudad de México son el ejemplo paradigmático de la dualidad de modelos, pues coexisten sujetos legitimados, ambos sin ningún tipo de restricción. En el caso de Chiapas, tenemos que el Procurador tiene restringida su impugnación a normas generales del Congreso Local, mientras que el Gobernador no tiene una restricción similar. Finalmente, es bastante peculiar el caso de Tlaxcala. En Tlaxcala, tanto el gobernador como el procurador tienen restringido su ámbito de impugnación.

Por último, analizaremos la última de las potenciales posturas frente a la legitimación del ejecutivo en las entidades federativas: la ausencia de ella. Aquí el caso a considerar es Guanajuato que ha sido el más restrictivo de los Estados en configurar la legitimación (sólo ha legitimado a minorías parlamentarias y Comisión de Derechos Humanos). A nuestro juicio, la legitimación del ejecutivo puede resultar bastante útil en tanto es un sujeto no legitimado por la jurisdicción federal, legitimación que sí comparten las minorías de las Entidades Federativas. En Guanajuato, el ejecutivo no tiene una elección optativa y debe acudir, en su caso, directamente a la Suprema Corte cuando proceda plantear una controversia sub specie legis.

Como balance general, podemos sostener que la legitimación indirecta del ejecutivo, como en los modelos de Quintana Roo, Nayarit y Nuevo León parece merecedora de un balance similar al federal. Más problemas presentan las Entidades Federativas que han mantenido la dualidad de legitimaciones, pues tal dualidad carece de un propósito claro y firme.

\section{Las minorías parlamentarias}

Las minorías parlamentarias han sido el sujeto legitimado por excelencia en la jurisdicción constitucional local. En cuanto a la determinación de las minorías, todas las Entidades Federativas han seguido un modelo porcentual y no han prefijado el número exacto de diputados para interponer la acción de inconstitucionalidad.

Los porcentajes para acudir a la jurisdicción constitucional local han variado en las distintas entidades federativas. La clásica opción del 33\% o de 1/3 del Congreso, a modo del modelo federal, ha sido mantenida por Veracruz, Estado de México, Quintana Roo, Ciudad de México, Nayarit, Yucatán y Guanajuato. Las entidades federativas anteriormente mencionadas mantienen identidad de sujetos respecto a la jurisdicción federal. 
Esta revista forma parte del acervo de la Biblioteca Jurídica Virtual del Instituto de Investigaciones Jurídicas de la UNAM

Nuevo León es un caso curioso al ser el único sistema a nivel de entidades federativas que no ha establecido constitucionalmente el porcentaje de la minoría que puede impugnar normas. ${ }^{41}$ Esta configuración materialmente delegó a la ley reglamentaria los porcentajes minoritarios. ${ }^{42}$ Aunque un anteproyecto inicial establecía un porcentaje reducido del $20 \%$ en $2009,{ }^{43}$ la Ley Reglamentaria del Artículo 95 de la Constitución de Nuevo León de 2014 terminó empleando el clásico porcentaje de 33\% en su versión definitiva (artículo 61).

Las demás Entidades Federativas han reducido los números de la legitimación. Esta reducción del elevado porcentaje que emplea el modo federal es deseable y establece posibilidades ulteriores de impugnación: No todas las minorías con capacidad de impugnación en las Entidades Federativas podrían hacer lo propio en el modelo federal.

Así, Oaxaca ha establecido el 30\% de los diputados como sujeto legitimado. Tlaxcala ha disminuido aún más los porcentajes al requerir al 25\% del cuerpo legislativo. Coahuila es la Entidad Federativa con el porcentaje más bajo al solicitar el 10\% del cuerpo legislativo para impugnar la constitucionalidad de una norma. Tlaxcala, en un toque original, ha consagrado legitimación también para impugnar normas provenientes de ayuntamientos o consejos electorales, a los diputados electos en el distrito respectivo.

Finalmente, de nueva cuenta resalta Sonora por su negativa configuración. No sólo no ha reducido los porcentajes de participación, sino que los ha incrementado a un 35\% (artículo 166, fracción II, apartado A, incisos b y c). Esta altísima modalidad de legitimación es absolutamente inexplicable por varias razones. En primer término, juega en contra de la funcionalidad del modelo el incrementar los números mínimos de legitimación. En segundo término, ello es antinatural ante la configuración del congreso local. El congreso de Sonora se compone por 21 diputados por mayoría

41 Literalmente, la Constitución Política de Nuevo León, dispone en el párrafo II de su artículo 95: "Esta acción de inconstitucionalidad podrá ser promovida por los diputados, tratándose de normas generales expedidas por el Congreso del Estado, y por los regidores, tratándose de normas generales expedidas por su respectivo ayuntamiento, en los términos que determine la ley reglamentaria".

42 Sin embargo, tal delegación puede tener un carácter potencialmente problemático al poder vaciar de contenido el citado artículo constitucional. ¿No podría una delegación irracional establecer el porcentaje del $100 \%$ de los diputados como mínimo de impugnación?

43 Véase el Diario de Debates núm. 321-LXX1-S.0, segundo periodo, año III, lunes, 25 de mayo: http://www.hcnl.gob.mx/trabajo_legislativo/pdf/debates/1766.pdf.

Cuestiones Constitucionales, Núm. 44, Enero-Junio 2021

ISSN: $2448-4881$ 
Esta revista forma parte del acervo de la Biblioteca Jurídica Virtual del Instituto de Investigaciones Jurídicas de la UNAM

relativa y 12 diputados por representación proporcional. Es decir, su integración natural es de 33 diputados. Frente a ello, la tercera parte arroja números enteros (11 diputados) mientras que el 35\% arroja 11.55 diputados. Es decir, la diferencia es reducida y fraccionaria pero únicamente da pie a complejos debates sobre si el porcentaje debe ser elevado o disminuido en números enteros (es decir, si se requieren 11 diputados o 12). Por tanto, era mucho más sencillo mantener el 33\% federal en caso de no querer reducir los porcentajes, que elevarlo a un porcentaje que no sólo no operativita el modelo, sino que tampoco arroja números enteros facilitando la presentación clara de la acción.

\section{Comisiones de Derechos Humanos}

Las Comisiones de Derechos Humanos han sido concebidas como sujetos legitimados frecuentes. Lo anterior tiene un aliciente indudable en su legitimación a nivel federal y la consecuente réplica en las Entidades Federativas. Los Estados de Chiapas, Nayarit, Tlaxcala y Estado de México han mantenido la legitimación federal, aunque con un enfoque diverso. ${ }^{44}$

En la doctrina española se ha señalado que la limitación de la legitimación al ámbito competencial (impugnación de normas contrarias a derechos humanos/fundamentales) era una manera sensata de evitar la politización de órganos defensores de derechos humanos (al ceñir el recurso a las competencias propias del sujeto legitimado, como argumentan Díaz (2010: 316) y Torres (2012: 12). Así parecen haberlo entendido Chiapas y Nayarit, al haber acotado la posible impugnación. Las fórmulas utilizadas son diversas. Chiapas legitima al presidente del Consejo Estatal de Derechos Humanos en el ámbito de su competencia; expresión que debe entenderse, a nuestro juicio, no sólo referida a los derechos humanos, sino también al funcionamiento orgánico del propio cuerpo (facultad de impugnar una norma por motivos competenciales adversos a la Comisión de Derechos Humanos). De esta forma, podríamos predicar que la redacción de Chiapas sí da pie para que curiosamente se emplee la acción de inconstitucionalidad como una controversia constitucional contra una

44 Coahuila mantuvo históricamente la legitimación, pero terminó por eliminarla en reforma constitucional de 2017. 
Esta revista forma parte del acervo de la Biblioteca Jurídica Virtual del Instituto de Investigaciones Jurídicas de la UNAM

norma - un conflicto competencial encubierto - mientras que lo anterior sería mucho más difícil en Nayarit, donde la expresión elegida ha sido "en contra de normas generales que vulneren los derechos fundamentales previstos en esta constitución".

Compleja es la extraña acotación de Guanajuato, introducida en reforma constitucional de 2015, que permite que la comisión local impugne normas únicamente en materia de acceso a la información pública y protección de datos personales. La acotación es verdaderamente inexplicable. Priva de funcionalidad a un sujeto destinado a cuestionar normativa que vulnere derechos humanos, que ya contaba con la legitimación para impugnar tanto derechos humanos en general como acceso a la información ante la jurisdicción federal, ¿por qué limitar a un sujeto que debería permitirle funcionalidad al sistema?

Sin embargo, existen otras entidades federativas que no han consagrado los límites correspondientes. En esta línea ubicamos a Tlaxcala (legitima a la Comisión) y al Estado de México (legitima a su presidente). En ambos ordenamientos no encontramos ninguna limitación respecto a la materia de impugnación. Por tanto, en Tlaxcala y Estado de México es posible abrir el debate que en España se ha venido mencionando previamente sobre la libre impugnación. No encontramos ni en los textos constitucionales ni en las leyes reglamentarias o iniciativas/exposiciones de motivos, elementos que nos permitan valorar si la ausencia de restricción se debe al deseo explícito de libre impugnación, si ha sido una omisión no deliberada o si se ha presupuesto que la lógica orgánica llevará a la Comisión de Derechos Humanos sólo a impugnar este tipo de leyes.

Nuevamente aquí tenemos la necesidad de una correcta articulación de modelos. Las comisiones de derechos humanos ya se encuentran legitimadas en la jurisdicción federal. Por ello, la ausencia de su legitimación no conduce a un cambio tan drástico en el estado actual de las cosas. El cambio notorio se dará cuando las Constituciones locales hayan reconocido un derecho que no encuentre reconocimiento análogo en la Constitución federal o en un tratado internacional, hipótesis ante la cual es posible recurrir a la jurisdicción local pero no a la federal, si atendemos al propio texto de la CPEUM. Las entidades federativas que sí han concedido legitimación a las comisiones locales, les han permitido optar entre acudir directamente a la Suprema Corte de Justicia o acudir al propio órgano de control local, pero sin cambiar el parámetro de control en materia federal. 
Esta revista forma parte del acervo de la Biblioteca Jurídica Virtual del Instituto de Investigaciones Jurídicas de la UNAM

También debe considerarse que, si llegase a eliminarse del modelo federal la legitimación de las Comisiones Locales, el debate podría reabrirse acerca de la conveniencia de su legitimación de lege ferenda en la vía local.

Otro cambio perceptible en el modelo se presenta respecto al caso de Tlaxcala y Estado de México. Dada la limitación establecida por el multicitado artículo 105, II, g), las comisiones en Tlaxcala y Estado de México podrían decidir, en casos marginales, acudir ante el órgano de control local para impugnar una norma que no tenga relación con derechos humanos. En este caso, la única vía sería la jurisdicción constitucional local, a efectos de evitar las objeciones sobre la ausencia de conexión con derechos humanos.

\section{La legitimación de los partidos políticos estatales:}

\section{¿Una acrítica traslación?}

Un sujeto que ha aparecido con mucha menor frecuencia en la jurisdicción constitucional local son los partidos políticos locales. De los sistemas de justicia constitucional en comento, sólo Tlaxcala, Sonora, Ciudad de México y Coahuila han consagrado su legitimación.

La razón de que sean un sujeto poco frecuente en la legitimación procesal local proviene del propio artículo 105 constitucional, reformado en 1996 para sostener que la única vía para plantear la no conformidad de las leyes electorales a la Constitución es la prevista en el propio artículo 105. Sin embargo, a pesar de que una lectura rápida del precepto nos podría indicar una exclusión de todo control electoral por instancia distinta, la solución no es tan sencilla. Es obvio que cuando la Constitución federal se refiere a la "no conformidad de leyes electorales a la Constitución" se refiere a la Constitución Política de los Estados Unidos Mexicanos. Aquí es cuando podemos encontrar un punto de articulación entre las dos jurisdicciones. Una interpretación posible es entender que lo que prohíbe el multicitado 105 es que la jurisdicción constitucional local controle la constitucionalidad de las normas locales tomando como parámetro el texto federal. Cierto es que la amplitud de los principios constitucionales genera que de una u otra manera se puedan encajar en su seno distintas violaciones a la normativa local, pero ello no descarta casos marginales en que una potencial regulación casuística de una Entidad Federativa plantee una 
Esta revista forma parte del acervo de la Biblioteca Jurídica Virtual del Instituto de Investigaciones Jurídicas de la UNAM

violación a la Constitución local que no es, a su vez, una violación a la Constitución federal.

De otro modo, si concebimos que la restricción planteada en el artículo 105 es absoluta (postura bastante extendida), debemos entender que la legitimación en Tlaxcala y Coahuila no produce efectos reales en materia electoral puesto que la normativa electoral debe analizarse en exclusiva por la jurisdicción federal. Guanajuato y Quintana Roo parecen ser partícipes de esta postura, al haber establecido en sus respectivos ordenamientos limitaciones textuales al conocimiento de la materia electoral.

Así, los partidos políticos, igualmente legitimados en la Constitución federal, deberán acudir a la Suprema Corte y no al órgano de control local. Incluso bajo esta postura, la diferente configuración de Coahuila respecto a Tlaxcala nos daría hipótesis de posible impugnación. Mientras que en Tlaxcala se ha configurado una legitimación "en asuntos de materia electoral", Coahuila no ha establecido restricción alguna. Se produce así la particular situación de que, a diferencia del modelo federal, los partidos no tienen en Coahuila restringida la posibilidad de impugnar normas no electorales. Por tanto, aún ante la interpretación restringida de considerar que la Constitución federal sólo permite impugnar normas electorales a través de la acción de inconstitucionalidad federal, los partidos políticos en Coahuila (y no sólo los locales) pueden, siempre en teoría, invocar cualquier motivo de inconstitucionalidad e impugnar cualquier tipo de norma.

Creemos que el modelo de Coahuila no fue diseñado con la intención de darle una facultad irrestricta de impugnación a los partidos políticos. Tales entidades no son órganos de suficiente peso ni de imparcialidad garantizada como para ser considerados el Hütter der Verfassung kelseniano y la facultad de la que son ingenuamente provistos acarrea la posibilidad de un desequilibrio político. Piénsese que tal concepto cambia el entendimiento de la legitimación del 10\% de los integrantes del Poder Legislativo que con tanta generosidad estableció Coahuila. ¿Por qué Coahuila configuraría una legitimación tan generosa en materia de minorías parlamentarias para inmediatamente volverla innecesaria legitimando in toto a los partidos políticos? La inocente omisión de Coahuila nos conduce a la paradoja de que todo partido político (sin importar si no es capaz de alcanzar el porcentaje minoritario para impugnar) puede utilizar la acción de inconstitucionalidad. Curiosamente, la única hipótesis en donde las fracciones b) y f) no serían coincidentes, se produce cuando el $10 \%$ del cuerpo legislativo que 
Esta revista forma parte del acervo de la Biblioteca Jurídica Virtual del Instituto de Investigaciones Jurídicas de la UNAM

desea impugnar no pertenece a un partido político (por ejemplo, derivados de candidaturas independientes, o de diputados sin partido, lo que es una hipótesis marginal).

\section{Legitimaciones locales peculiares}

Hemos analizado las legitimaciones frecuentes en la acción de inconstitucionalidad local. Quedan, sin embargo, por mencionar la existencia de legitimaciones peculiares. Por un lado, Coahuila, Ciudad de México, Oaxaca, Sonora y Yucatán conceden legitimación a sus órganos constitucionales autónomos. Por otro lado, Tlaxcala concede legitimación a las universidades.

En el primero de los casos, la legitimación se ha concedido al "organismo público autónomo" (Coahuila y Yucatán), a "los órganos autónomos del Estado" (Oaxaca) o a los "organismos públicos autónomos" (Sonora), legitimación que encuentra una mención histórica en Quiroz (2006: p. 129). Por su parte, Ciudad de México legitima a "cualquier organismo constitucionalmente autónomo". Yucatán, Ciudad de México y Oaxaca han establecido acotaciones a la función de los órganos autónomos de las normas impugnadas. Sin embargo, Coahuila y Sonora han omitido establecer una limitación del objeto impugnatorio, por lo que consideramos que, en tal ordenamiento, la impugnación es libre. Es decir, es innecesario demostrar que impugnan normas relacionadas con sus funciones. Para el caso de Coahuila, debe reputarse negativa la posibilidad de que la impugnación no se encuentre sujeta a una materia concreta. La falta de límites a la legitimación de los órganos constitucionales autónomos puede acarrear los riesgos de la politización de sus impugnaciones. Aquí (Coahuila) la legitimación resulta más peculiar dado que, como hemos señalado anteriormente, los organismos públicos autónomos gozan ya de legitimación en la controversia constitucional local. La posibilidad de plantear una controversia constitucional sub specie legis ya ofrecía un mecanismo de defensa del régimen competencial de cada órgano constitucional autónomo. Por tanto, la ulterior legitimación en la acción de inconstitucionalidad no tiene tintes competenciales.

Si la legitimación de los organismos constitucionales autónomos suscita ya fuertes dudas en la acción de inconstitucionalidad, más aún lo es la opción de legitimar a las universidades. En el caso de normas de la entidad 
Esta revista forma parte del acervo de la Biblioteca Jurídica Virtual del Instituto de Investigaciones Jurídicas de la UNAM

federativa, Tlaxcala ha legitimado expresamente a la Universidad Autónoma de Tlaxcala y en el caso de normas provenientes de un ayuntamiento o consejo municipal, a cualquier universidad pública. Se ha convertido, así, en la única entidad federativa en establecer este tipo de legitimación (cuya regulación no se aborda en su ley orgánica). Debe entenderse que la impugnación debería hacerse, en su caso, a través del consejo rector, su máximo órgano.

Debemos calificar a esta legitimación, cuando menos, como peculiar e imaginativa. Las Universidades no pertenecen formalmente al Estadoaparato ni se desempeñan como defensores de derechos fundamentales como sí lo hacen las comisiones de derechos humanos. Por tanto, la razón subyacente a su legitimación no es en definitiva ni la vindicación de competencias propias, ni la defensa de derechos humanos - no por lo menos en lo que atañe a su función-. Puede argumentarse, en cambio, que las Universidades, como centros de investigación y docencia pueden aportar ulteriores motivos de inconstitucionalidad por la cualificación especial de sus académicos. Empero, tal legitimación puede precisamente producir un turbio panorama politizado en centros que deben destacarse precisamente por la búsqueda de conocimiento fuera de toda consideración política. No debe descartarse el hecho de que, en la actualidad, se produce también una interesante relación entre los académicos y las comisiones de derechos humanos, tanto a nivel federal como a nivel local. Ello nos lleva a sostener que la legitimación de las Universidades no es imprescindible para aportar razones académicas en el debate constitucional. También parece inconsistente la distinción entre el ámbito territorial de validez de las normas que las distintas Universidades pueden impugnar. Así, mientras la Universidad de Tlaxcala puede impugnar normas estatales, las demás Universidades sólo pueden hacerlo respecto a normas de un ayuntamiento o cabildo municipal. ${ }^{45}$ No existe una razón que justifique la distinción.

A pesar de que una acción popular puede despertar recelos a nivel federal, ésta podría tener cabida a nivel local con un diseño cuidadoso. El marco comparativo alemán y la popularklage del Land de Baviera demuestran que, en ciertas circunstancias, la acción popular puede resultar funcional

45 Aunque podría pensarse que en realidad se han establecido dos ámbitos separados de impugnación, la Universidad de Tlaxcala sí podría impugnar normas de un Ayuntamiento o Cabildo Municipal porque calificaría bajo la expresión de "cualquier Universidad pública del Estado".

Cuestiones Constitucionales, Núm. 44, Enero-Junio 2021

ISSN: 2448-4881 
Esta revista forma parte del acervo de la Biblioteca Jurídica Virtual del Instituto de Investigaciones Jurídicas de la UNAM

y otorgar una amplia garantía a la Constitución sin necesariamente generar una congestión de procesos. La decisión, sin embargo, sigue perteneciendo enteramente a las Entidades Federativas y la opción consciente de otorgar legitimación sólo a actores de naturaleza institucional no resulta incongruente ni criticable. Dado el pluralismo del Estado Federal mexicano, podría ser interesante a futuro valorar el comportamiento de tales acciones populares que, potencialmente, podrían encontrar amoldamiento en los modelos locales.

Sólo dos modelos parecen haberse potencialmente decantado por esta posibilidad Coahuila (indirectamente) y Ciudad de México (directamente). En el caso de Coahuila sostuvimos que su artículo 158 constitucional consagra una especie de legitimación indirecta a cualquier ciudadano empleando de intermediario al órgano protector de derechos humanos. La práctica parece haber demostrado que la comisión local no actúa como un simple receptor y ejecutor de la petición, sino que analiza motu proprio los méritos de la propuesta. Finalmente, el ejercicio último de la legitimación recae en ésta. Cuestión distinta es la Ciudad de México que establece sin ambages una popularklage pero de configuración defectuosa.

El artículo 36, apartado $\mathrm{C}$, numeral 1, inciso $\mathrm{f}$ de la Constitución de la Ciudad de México confiere legitimación a "la ciudadanía que considere afectados sus derechos por la vigencia de dicha ley, siempre que la solicitud cuente con al menos cinco mil firmas de las personas inscritas en la lista nominal de electores de la ciudad". Este requisito no es modulado en la Ley de la Sala Constitucional de la Ciudad de México, cuyo artículo 80, fracción VI reproduce textualmente la redacción constitucional.

La legitimación, por tanto, contiene dos elementos esenciales, ${ }^{46}$ a) número directo de legitimación, y b) afectación alegada. Así, en primer término, se establece la necesidad de conseguir 5,000 firmas. Tal requi-

46 No nos referimos, naturalmente, a otros elementos de la acción. Por tanto, no me adentro en el debate de si la redacción permite o no impugnar normas publicadas pero que no hayan entrado en vigor (hipótesis claramente permitida a nivel federal y que ha ocurrido en la práctica como en la AI 25/2016 y sus acumuladas). Para un comentario sobre ello Herrera y Rivera (2017). Así, dado que se requiere que los ciudadanos se sientan afectados "por la vigencia de la ley" es válido cuestionarse si una interpretación formalista a posteriori no restringirá la impugnación precondicionándose a la validez de la norma. Dada la forma de computar la oportunidad éste no parece que sea el caso pues el plazo sigue corriendo a partir de la publicación y promulgación de la norma (artículo 36 de la Constitución, apartado B, numeral 1, inciso c y artículo 79 de la Ley de la Sala Constitucional). 
Esta revista forma parte del acervo de la Biblioteca Jurídica Virtual del Instituto de Investigaciones Jurídicas de la UNAM

sito se expresa en un número directo y no en un porcentaje, lo que al menos facilita que el número no se incremente conforme se incremente la población de la Ciudad de México. Para un modelo de legitimación procesal local como Ciudad de México, el número parece ser aún bastante alto. Empero, dada la densidad poblacional de la Ciudad de México, esta valoración variaría si estuviésemos en presencia de un modelo nacional. Piénsese que la población de Austria (poco menos de 9 millones) es similar a la de la Ciudad de México (igualmente, poco menos de 9 millones si no se toma en cuenta la zona conurbada y la población flotante). Sin embargo, las condiciones de acceso difieren si tomamos en cuenta la ya existencia de una jurisdicción federal y la intención consecuente de los constituyentes locales de presumiblemente potenciar el uso de la justicia constitucional local.

Por otro lado, también debe considerarse limitativo que tales ciudadanos únicamente puedan ser contabilizados entre los inscritos en la lista nominal ${ }^{47}$ y no entre los residentes de la ciudad. Pareciera que el constituyente capitalino asocia el control constitucional con la participación política, pues usualmente referéndums o apoyo ciudadano tiene como prerrequisito la inscripción al listado nominal. Empero, el control constitucional abstracto no parece que tenga asociada esta forma de participación, sino más bien el deseo de control constitucional de la norma cuya única acotación específica razonable pareciera ser la residencia en el ámbito de validez de la norma.

Ello nos lleva al segundo elemento cuya formulación es innecesaria. Dado que nos encontramos en un mecanismo de control abstracto normativo, no parece técnicamente correcto que se haya establecido a la afectación considerada como un elemento de la formación de legitimación. Sobre ello habría dos hipótesis potenciales.

En primer término, podríamos considerar una hipótesis rígida en que se solicitase a cada uno de los firmantes acreditar, al menos indiciariamente, la alegada afectación de la norma (i.e., demostrar la conexión de la norma con su esfera jurídica). Ello implicaría crear un mecanismo para eliminar firmas individuales que no cumplan el requisito. Dado que la Ley de la Sala Constitucional de la Ciudad de México no añade requisitos,

47 El actual listado nominal, a 20 de septiembre de 2019 consta de 7,601,174. Datos Oficiales del Instituto Nacional Electoral (INE). Disponible en https://bit.ly/2wqDwib (última consulta 30 de septiembre de 2019).

Cuestiones Constitucionales, Núm. 44, Enero-Junio 2021

ISSN: 2448-4881 
Esta revista forma parte del acervo de la Biblioteca Jurídica Virtual del Instituto de Investigaciones Jurídicas de la UNAM

parece que esta opción ha sido afortunadamente descartada. Por otro lado, una segunda hipótesis - la adoptada por la norma - consideraría al requisito como meramente formal. Tomando en cuenta el verbo empleado "considere" afectados sus derechos, podría interpretarse que el requisito es únicamente de apreciación interna ${ }^{48}$. Por tanto, a efectos de ambas hipótesis y dada la naturaleza abstracta de la acción de inconstitucionalidad, resultaba de mayor coherencia en el diseño del modelo de control local el simplemente haber omitido la afectación considerada y sin ambages establecer la legitimación directa de un grupo de personas, sin importar si resienten o no una afectación.

En ese sentido, sólo un análisis empírico posterior, imposible en este caso, demostrará si efectivamente se posibilitó un verdadero mecanismo de impugnación, o si los números resultaron demasiado gravosos en la conformación del grupo legitimado.

\section{CONSIDERACIONES FINALES}

A lo largo del presente artículo se ha argumentado que el establecimiento de modelos de justicia constitucional local debe considerarse positivo en tanto muestra un cambio del concepto de Constitución local hacia una visión normativa y un fortalecimiento del federalismo.

En esa tesitura, existen otros modelos federales, como el alemán, que han logrado con éxito mantener sistemas de justicia constitucional local. Este modelo se basa en los principios de subsidiariedad y colaboración de jurisdicciones, la previsión de la posibilidad de la existencia de modelos desde la Constitución federal, la demarcación de zonas propias de la juris-

48 Algo similar ocurre con el artículo $5^{\circ}$ de la Ley de Amparo, que define al quejoso, parcialmente, como quien "aduzca" la titularidad del derecho subjetivo o el interés legítimo individual o colectivo. La forma del verbo "aducir" no implica la plena demostración de la titularidad, lo que constituye un objeto del fondo del asunto (Sánchez, 2016: p. 95). Sin embargo, la cuestión difiere a pesar de la formulación similar, pues la Ley de Amparo sí consagra como causal de improcedencia la ausencia de tal interés (fracción XII del artículo 61 de la Ley de Amparo). Ello ha llevado a la Corte a hablar de una existencia "indiciaria" (por ejemplo, en la tesis 1a. CXXIII/2013 (10a.) de la Primera Sala). Ello no es aplicable analógicamente a este caso de legitimación popular en el que, a nuestro juicio, la simple firma que denota el consentimiento para formar parte del grupo que impugna la norma, debe implicar en consecuencia también, el cumplimiento del requisito de considerar resentir la afectación enunciada por la norma. 
Esta revista forma parte del acervo de la Biblioteca Jurídica Virtual del Instituto de Investigaciones Jurídicas de la UNAM

dicción constitucional local y la tendencia a la legitimación de ulteriores sujetos o reducción de los requisitos de sujetos análogos a los legitimados a nivel federal. Esta experiencia es útil a modelos federales como el mexicano que desean establecer una jurisdicción constitucional local.

A contrario sensu, la falta de un principio de subsidiariedad/colaboración de jurisdicciones en algunas materias (que deriva en la falta de una zona exclusiva de la jurisdicción constitucional local) así como la falta de la definitividad de sus decisiones, ha dado por consecuencia directa la inestabilidad de los modelos y su falta de consolidación. En los modelos locales se aprecia una tendencia clara a la duplicidad de legitimaciones y la reproducción de la legitimación a nivel federal. Sin embargo, varias Entidades Federativas han empleado modelos abiertos en controversias constitucionales, han incluido mayores sujetos legitimados en ambos procedimientos, disminuido los porcentajes de las minorías parlamentarias y ofrecen algunos ejemplos interesantes en que se produce duplicidad de legitimación, pero no de ámbitos impugnatorios. En este punto, conviene recordar también que es posible que sujetos no legitimados en los mecanismos de control constitucional local, controviertan ante la jurisdicción federal las decisiones tomadas en los mecanismos locales.

Una inadecuada articulación puede generar una compleja esfera gris en la que las disputas se inicien localmente, pero cuyos actores políticos inconformes con las decisiones intenten "escalar" al Poder Judicial de la Federación tales mecanismos y vía amparo, u otras vías procesales, se erija el poder judicial federal en un mero revisor. Esta temática desborda los alcances de este trabajo, pero resulta necesario realizar sobre ella una mayor investigación si es que pretendemos encontrar un diseño coherente de modelos articulados.

Aunado a lo anterior, debe apuntarse que un modelo de justicia constitucional local funcional precisa, necesariamente, un blindaje fuerte en materia de independencia judicial. Esto es, no sólo es necesario establecer un adecuado deslinde de jurisdicciones, sino que debe ofrecerse a la jurisdicción local un revestimiento de garantías orgánicas suficientes que la protejan contra intentos ilegítimos de intromisiones. El debate que con frecuencia se da respecto a la eliminación del amparo por la pretendida "ineficacia" de la jurisdicción local, tiene plena cabida cuando se concibe a ésta como garante último de la Constitución local. Es necesario diseñar poderes judiciales locales sólidos en que los ejecutivos o parlamentos lo- 
Esta revista forma parte del acervo de la Biblioteca Jurídica Virtual del Instituto de Investigaciones Jurídicas de la UNAM

cales tengan una menor injerencia sobre los juzgadores, lo que permita que se erijan en árbitros de conflictos políticos de manera definitiva.

La valoración de la legitimación a nivel local es demasiado compleja de realizar si antes no se hace una clara articulación de modelos. En ausencia de una articulación precisa, la duplicidad de controles y legitimaciones dará como resultado modelos locales cuyo desempeño empírico es incapaz de servir de base para análisis concluyentes.

Para resolver el problema de la articulación hay dos grandes posibilidades. Una reforma constitucional federal que cree una articulación idónea e indisputada de modelos (Coello, 2006: p. 347) o una jurisprudencia tópica que fije lentamente criterios de deslinde. Sólo con posterioridad podría emitirse una evaluación precisa de la legitimación en las acciones de inconstitucionalidad y controversias constitucionales en los modelos locales.

\section{FUENTES CONSULTADAS}

Arteaga, E. (2002). La Constitución local y su defensa. En Ferrer MAC-GREGOR, E. y VeGA, R. (coords.). Justicia constitucional local. Querétaro: Fundap.

Astudillo, C. (2006). La justicia constitucional local en México: presupuestos, Sistemas y Problemas. Boletín Mexicano de Derecho Comparado. Núm. 115.

BendA, E. y KleIn, E. et al. (2010). Verfassungsprozessrecht. Munich: C.F. Müller.

BetTIENELLI, E. (1993). Qualche osservazione controcorrente sul valore non definitivo delle ordinanze di ammisibilità dei ricorsi relativo ai conflitti di Attribuzione tra i Poteri dello Stato. En AnZON, A. y CARAVITA, B. (eds.). La Corte costituzionale e gli altri poteri dello Stato, Turín: Giappichelli editore.

BoHn, B. (2010). Verfassungsprozessrecht der Popularklage. Berlín: Duncker \& Humboldt.

BuRMEISTER, J. (1983). Vorlagen an das Bundesverfassungsgericht nach Art. 100 Abs. 3 GG. En STARCK, C. y KLAUS, S. Landesverfassungsgerichtsbarkeit. Baden-Baden: Nomos Verlag. 
Esta revista forma parte del acervo de la Biblioteca Jurídica Virtual del Instituto de Investigaciones Jurídicas de la UNAM

Bustillos, J. (2009). La realidad de la justicia constitucional local mexicana en el siglo XXI”. Cuestiones Constitucionales. Núm. 21.

Bustillos, J. (2013). Amparo federal vs. Amparo local: la incertidumbre de la protección constitucional local frente a la jurisdicción federal. Reforma Judicial, núm. 15-16.

Coello, R. (2006). Definitividad de las resoluciones de los medios de control de la constitucionalidad competencia de los tribunales locales. En GonzÁlez, M. \& FERRER MAC-GregOR, E. (coords.). La justicia constitucional en las entidades federativas. México: Porrúa.

Coello, R. (2008). Articulación de los medios de control de la constitucionalidad nacionales y locales. En FERRER MAC-GREGOR, E. y ZALDÍVAR, A. La ciencia del derecho procesal constitucional. Tomo III. México: IIJ-UNAM.

DíAz, M. (2010). Defensor del Pueblo y justicia constitucional: entre la declaración de intenciones y el exceso competencial. Teoría y Realidad Constitucional. núm. 26.

FERrer MAC-Gregor, E. (2003). Hacia un derecho procesal constitucional local en México. Anuario de Derecho Constitucional Latinoamericano.

FigueroA, G. (2013). La giustizia costituzionale locale in Messico. En BAGNI, S. (ed.). Giustizia Costituzionale Comparata. Bolonia: Bolonia University Press.

FinKELBURG, K. (2008). Auch ein langer Weg: Die Entstehung der Verfassungsgerichtsbarkeit in Berlin. En AA.VV. Festschrift für das Schleswig-Holsteinische Landesverfassungsgericht. Kiel: Lorenz-vonStein-Institut.

GRÖPL, C. y WINDTHORST, K. et al. (2013). Grundgesetz Studienkommentar. Munich: C.H. Beck Verlag.

HAAS, M. (2006). Der Verfassungsgerichtshof des Freistaates Sachsen. Berlín: Berliner Wissenschafts-Verlag.

Halle, M. (2004). Landesverfassungsgericth. En Kilian, M. Verfassungshandbuch Sachsen-Anhalt. Baden-Baden: Nomos.

HeCKer, W. (2002). Hessisches Landesrecht. Baden-Baden: Nomos.

Herrera, A. y Rivera M. (2017). La Suprema Corte y su candado a la legitimación en la acción de inconstitucionalidad. Nexos. México. 
Esta revista forma parte del acervo de la Biblioteca Jurídica Virtual del Instituto de Investigaciones Jurídicas de la UNAM

HeusCH, A. (2010). Artikel 75. Kommentar. En HeusCH, A. y SCHÖNENBROICHER, K. Die Landesverfassung Nordrhein-Westfalen. Kommentar. Siegburg: Verlag Reckinge.

HeYDE, W. (1983). Überblick über die Verfahren vor de Landesverfassungsgerichten mit Tabellen über die Häufigkeit der Verfahren. En STARCK, C. y KlAus, S. Landesverfassungsgerichtsbarkeit. BadenBaden: Nomos Verlag.

HÜCKSÄDT, G. (2008). Zwölf Jahre Verfassungsgerichtbarkeit in Mecklenburg-Vorpommern. En AA. VV. Festschrift für das Schleswig-Holsteinische Landesverfassungsgericht. Kiel: Lorenz-von-Stein-Institut.

HÜPPER, G. (2010. Der Staatsgerichsthofs des Landes Niedersachen: Institution und Entscheidungstätigkeit seit Gründung. Baden-Baden: Nomos.

JoHAnN, P. (2000). 50 Jahre Landesverfassung Nordrhein-Westfalen, Düsseldorf: Rheinland-Verlag GmbH.

JutzI, S. (2005). Staats- und Verfassungsrecht. En LEY, R. \& SiEGFRID, J. (coords.). Staats- und Verwaltungsrecht für Rheinland-Pfalz. BadenBaden, Nomos.

Jutzi, S. (2013). Artikel 80. Kommentar. En Linck, J. y Baldus, M. et al (coords.), Die Verfassung des Freistaats Thüringen. Baden-Baden: Nomos.

LinDneR, J. (2011). Bayerisches Staatsrecht. Stuttgart: Richard Boorberg Verlag.

LÖSING, N (2002). La doble jurisdicción constitucional en Alemania. En FERRER MAC-GREGOR, E. y VEGA, R. (coords.). Justicia constitucional local. Querétaro: Fundap

Mazziotti, M. (1972). I Conflitti di attribuzione fra i poteri dello stato. Milán: Giuffrè.

MüLLER, K. (2005). Verfassung des Landes Thüringen: Ein politischjuristisches Lesebuch nach Art eines Kommentars. Neukirchen-Vluyn: Verlag für Ausbildung und Verwaltung.

Pegoraro, L. (2017). Hacia una nueva sistemática de los modelos de justicia constitucional. En EstuPIÑÁn, L. et al. Tribunales y justicia constitucional. Bogotá: Universidad de Bolonia. 
Esta revista forma parte del acervo de la Biblioteca Jurídica Virtual del Instituto de Investigaciones Jurídicas de la UNAM

PIEROTH, Bodo (2002). Organstreitverfahren vor dem Verfassungsgerichsthof. En AA. VV. Verfassungsgerichtsbarkeit in Nordrhein-Westfalen, Leipzig: Richard Boorberg Verlag.

QuirOz, C. (2006). La justicia constitucional local. En FERRER MAC-GREGOR, E. (coords.) La justicia constitucional en las entidades federativas. México: Porrúa.

RinKen, A. (1991). Staatsgerichtshof. En Kröning, V. \& Pottschmidt, G. et al. Handbuch der Bremischen Verfassung. Baden-Baden: Nomos.

Ríos, L. (2001). La garantía jurisdiccional de la constitucionalidad local. En GonzÁlez, M. y Cienfuegos, D. (coords.). Estudios de derecho constitucional local. Saltillo: Editorial Laguna.

RiverA, M. (2015), Las otras Constituciones: el constitucionalismo local en la encrucijada de la reforma constitucional. En ANDREWS, C. (ed.). Miradas a la historia constitucional de México. México, CIDE/CESOP.

Rivera, M. (2016). Las puertas de la Corte. México: Porrúa.

Rivera, M. (2017). Artículo 105. En Cossío, J. (coord.). Constitución Política de los Estados Unidos Mexicanos comentada. México: Tirant lo Blanch.

SACCO, R. (1991). Legal Formants: A Dynamic Approach to Comparative Law. The American Journal of Comparative Law, vol. 39, núm. 2.

SÁnchez, R. (2016). Las partes en el juicio de amparo. En Cossío, J. (coord.) La nueva ley de amparo. México: Porrúa.

SCHNEIDER, H., (1999). Entlastung des Bundesverfassungsgerichtes durch Ausbau oder Umbau der Landesverfassungsgerichtsbarkeit. En BogS, H. (coord). Urteilsverfassungsbeschwerde zum Bundesverfassungsgerich. Baden-Baden: Nomos.

Somma, A. (2015). Introducción al derecho comparado. Madrid: Universidad Carlos III.

StarcK, C. y Klaus, S. (1983). Landesverfassungsgerichtsbarkeit. Baden-Baden: Nomos Verlag.

TORRES, I. (2012). La legitimación en los procesos constitucionales en España. En NiEMBRO, R. y POMED, L. et al. (coords.). Jurisprudencia del Tribunal Constitucional Español. México: Porrúa.

Uribe, E. y Montes, A. (2011). Notas sobre un federalismo renovado en México y su vinculación con la justicia constitucional local para la 
Esta revista forma parte del acervo de la Biblioteca Jurídica Virtual del Instituto de Investigaciones Jurídicas de la UNAM

garantía de los derechos fundamentales, Cuestiones Constitucionales, núm. 25, 267-291.

WAACK, H. (2008). Der lange Weg Schleswig-Holsteins zu einem eigenen Landesverfassungsgericht. En AA. VV. Festschrift für das SchleswigHolsteinische Landesverfassungsgericht. Kiel: Lorenz-von-Stein-Institut. 